\title{
Vision Loss Shifts the Balance of Feedforward and Intracortical Circuits in Opposite Directions in Mouse Primary Auditory and Visual Cortices
}

\author{
Emily Petrus, ${ }^{1}$ Gabriela Rodriguez, ${ }^{2}$ Ryan Patterson, ${ }^{1}$ Blaine Connor, ${ }^{2}$ Patrick O. Kanold, ${ }^{3}$ and ${ }^{\mathbb{P}}$ Hey-Kyoung Lee ${ }^{1,2}$ \\ ${ }^{1}$ Solomon H. Snyder Department of Neuroscience, Zanvyl Krieger Mind/Brain Institute, and ${ }^{2}$ Cell, Molecular, Developmental Biology, and Biophysics \\ Graduate Program, Johns Hopkins University, Baltimore, Maryland 21218, and ${ }^{3}$ Department of Biology, University of Maryland, College Park, Maryland \\ 20742
}

Loss of a sensory modality leads to widespread changes in synaptic function across sensory cortices, which are thought to be the basis for cross-modal adaptation. Previous studies suggest that experience-dependent cross-modal regulation of the spared sensory cortices may be mediated by changes in cortical circuits. Here, we report that loss of vision, in the form of dark exposure (DE) for 1 week, produces laminar-specific changes in excitatory and inhibitory circuits in the primary auditory cortex (A1) of adult mice to promote feedforward (FF) processing and also strengthens intracortical inputs to primary visual cortex (V1). Specifically, DE potentiated FF excitatory synapses from layer 4 (L4) to L2/3 in A1 and recurrent excitatory inputs in A1-L4 in parallel with a reduction in the strength of lateral intracortical excitatory inputs to A1-L2/3. This suggests a shift in processing in favor of FF information at the expense of intracortical processing. Vision loss also strengthened inhibitory synaptic function in L4 and L2/3 of A1, but via laminar specific mechanisms. In A1-L4, DE specifically potentiated the evoked synaptic transmission from parvalbumin-positive inhibitory interneurons to principal neurons without changes in spontaneous miniature IPSCs (mIPSCs). In contrast, DE specifically increased the frequency of mIPSCs in A1-L2/3. In V1, FF excitatory inputs were unaltered by DE, whereas lateral intracortical connections in L2/3 were strengthened, suggesting a shift toward intracortical processing. Our results suggest that loss of vision produces distinct circuit changes in the spared and deprived sensory cortices to shift between FF and intracortical processing to allow adaptation.

Key words: circuit plasticity; cortical plasticity; cross-modal plasticity; excitatory synaptic transmission; inhibitory synaptic transmission

\section{Introduction}

Loss of one sense can trigger compensatory changes in many brain areas, including the primary sensory cortices of both spared and deprived senses, which are referred to as cross-modal plasticity (Bavelier and Neville, 2002). Blind individuals have better pitch discrimination and sound localization (Röder et al., 1999; Gougoux et al., 2004) and enhanced braille comprehension (Cohen et al., 1997). Although some of these changes are attributed to reorganization of the deprived cortex for processing the spared senses (Cohen et al., 1997), others are attributed to adaptive plasticity of the spared cortices (Sterr et al., 1998a, 1998b). Such systems-level plasticity likely reflects functional adaptation of

\footnotetext{
Received Dec. 7, 2014; revised April 16, 2015; accepted May 2, 2015.

Author contributions: E.P., P.O.K., and H.-K.L. designed research; E.P., G.R., R.P., B.C., and H.-K.L. performed research; E.P., G.R., R.P., and H.-K.L. analyzed data; E.P. and H.-K.L. wrote the paper.

This work was supported by the National Institutes of Health (Grant R01-EY022720 to H.-K.L. and P.O.K., Grant F31-NS079058 to E.P., and Grant 3R01-EY022720-02S1 to G.R.).

The authors declare no competing financial interests.

Correspondence should be addressed to Hey-Kyoung Lee, Johns Hopkins University, 3400 North Charles Street, Dunning Hall Room 348, Baltimore, MD 21218. E-mail: heykyounglee@jhu.edu.

DOI:10.1523/JNEUROSCI.4975-14.2015

Copyright $\odot 2015$ the authors $\quad 0270-6474 / 15 / 358790-12 \$ 15.00 / 0$
}

cortical circuits. Previous studies showed that in juveniles removing vision induces cross-modal synaptic changes in the supragranular layers of primary sensory cortices (Goel et al., 2006; Jitsuki et al., 2011; He et al., 2012; Zheng et al., 2014). In particular, these changes include a global decrease in AMPA receptor (AMPAR)-mediated miniature EPSCs (mEPSCs) in primary auditory (A1) and barrel (S1BF) cortices (Goel et al., 2006; He et al., 2012) and facilitation of long-term potentiation (LTP) at layer 4 (L4) to L2/3 synapses in S1BF (Jitsuki et al., 2011). Cross-modal synaptic plasticity is not restricted to loss of vision early in life because, in adults, a brief period of visual deprivation triggers potentiation of thalamocortical inputs to A1 (Petrus et al., 2014). Synaptic changes observed in A1 or S1BF after vision loss, respectively, require auditory or whisker inputs, but are not accompanied by gross changes in the bottom-up external sensory inputs (He et al., 2012; Petrus et al., 2014). These findings suggest that vision loss triggers cross-modal plasticity of circuitry in the spared sensory cortices, which is not likely a result of changes in the sensory drive. In addition to changes in the spared sensory cortices, loss of vision produces plasticity within V1. Binocular visual deprivation in particular leads to potentiation of mEPSCs in $\mathrm{L} 2 / 3$ of $\mathrm{V} 1$, which requires complete loss of vision (He et al., 
2012) and occurs through adulthood (Goel and Lee, 2007). Unlike changes in the spared cortices, visual deprivation does not alter the strength of thalamocortical synapses to V1-L4 and, similarly, deafening does not alter thalamocortical synapses in A1-L4 (Petrus et al., 2014). Collectively, these findings suggest that adaptation of the spared and the deprived sensory cortices may differ.

Here, we examined adaptation of FF and intracortical circuits in $\mathrm{A} 1$ and $\mathrm{V} 1$ after visual deprivation in adult mice. We found that 1 week of visual deprivation leads to circuit changes in A1 to preferentially amplify FF signals at the expense of intracortical inputs. In contrast, FF synapses in V1 did not change with visual deprivation, but intracortical lateral synapses to L2/3 strengthened. In addition, inhibitory circuits in A1 strengthened after visual deprivation, although the specific mechanism of adaptation differed depending on the lamina. Our results suggest that sensory loss leads to circuit adaptation that favors FF processing in the spared cortices while promoting intracortical processing in the deprived cortex.

\section{Materials and Methods}

Animals. Male and female C57BL/6J mice (The Jackson Laboratory) were raised in $12 \mathrm{~h} \mathrm{light} / 12 \mathrm{~h}$ dark conditions. At postnatal day 90 (P90), mice were dark exposed (DE) for $7 \mathrm{~d}$. Age-matched controls remained in normal light conditions (normal-reared, NR). DE animals were cared for using infrared vision goggles with dim infrared light. Some mice were returned to normal light conditions for $7 \mathrm{~d}$ to study the effect of light reexposure (LE). Layer 4-Cre mice (B6;C3$\mathrm{Tg}(\mathrm{Scnn} 1 \mathrm{a}-\mathrm{cre}) 3 \mathrm{Aibs} / \mathrm{J}$; The Jackson Laboratory) or male PV-Cre mice (B6;129P2-Pvalb ${ }^{\mathrm{tm} 1 \text { (cre)Arbr} / J ; ~ T h e ~ J a c k s o n ~ L a b o r a t o r y) ~ w e r e ~}$ also used, with Layer 4-Cre mice experiencing DE at P90, whereas PV-Cre mice were DE between P35 and P38. Only male PV-Cre mice between $\mathrm{P} 39$ and $\mathrm{P} 45$ were used for experiments measuring inhibitory synaptic transmissions. All experiments were approved by the Institutional Animal Care and Use Committees of Johns Hopkins University and University of Maryland and followed the guidelines of the Animal Welfare Act.

Cortical Channelrhodopsin-2 viral transfection. L4-Cre mice (B6;C3$\operatorname{Tg}($ Scnn1a-cre)3Aibs/J; The Jackson Laboratory) or PV-Cre mice (B6;

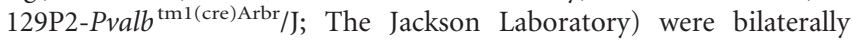
injected with double-floxed Channelrhodopsin-2 [ChR2; AAV9.EF1. dflox.hChR2(H134R)-mCherry.WPRE.hGH, Penn Vector Core, University of Pennsylvania]. Mice recovered on a heated surface and were returned to the animal colony, where they remained to produce sufficient ChR2 expression before experimental paradigms were initiated. A1-L4 was targeted with the following coordinates: bregma 2.92, lateral 3.6, depth 0.8 , whereas for V1-L4 targeting, we used: bregma -3.6 , lateral 2.5 , depth 0.43 . L4-Cre mice required 6-8 weeks of posttransfection incubation, whereas PV-Cre mice required 10-14 d before experimental use. Both species were injected between P21 and P25 and were housed with two to three same sex mice per cage during the recovery period.

Cortical slice preparation. Mice were deeply anesthetized using isoflurane vapors and decapitated after the disappearance of the corneal reflex. The brain was quickly removed and immersed in ice-cold dissection buffer containing the following (in $\mathrm{mm}$ ): 212.7 sucrose, 10 dextrose, 3 $\mathrm{MgCl}_{2}, 1 \mathrm{CaCl}_{2}, 2.6 \mathrm{KCl}, 1.23 \mathrm{NaH}_{2} \mathrm{PO}_{4} \cdot \mathrm{H}_{2} \mathrm{O}$, and $26 \mathrm{NaHCO}_{3}$, which was bubbled with a $95 \% \mathrm{O}_{2} / 5 \% \mathrm{CO}_{2}$ gas mixture. Brain blocks containing $\mathrm{V} 1$ and $\mathrm{A} 1$ were dissected and coronally sectioned into $300-\mu \mathrm{m}$-thick slices using a Vibratome 3000 plus microslicer (Ted Pella). Slices were then maintained in the dark at room temperature for $1 \mathrm{~h}$ in a holding chamber with artificial CSF (ACSF) containing the following (in $\mathrm{mm}$ ): $124 \mathrm{NaCl}, 5 \mathrm{KCl}, 1.25 \mathrm{NaH}_{2} \mathrm{PO}_{4} \cdot \mathrm{H}_{2} \mathrm{O}, 26 \mathrm{NaHCO}_{3}, 10$ dextrose, 2.5 $\mathrm{CaCl}_{2}$, and $1.5 \mathrm{MgCl}_{2}$, bubbled with $95 \% \mathrm{O}_{2} / 5 \% \mathrm{CO}_{2}$.

Analysis of L4-Cre expression of ChR2-mCherry. Fluorescent cells were visualized by offsetting the threshold intensity manually and were selected on the basis of spheres with a minimum radius of $13 \mu \mathrm{m}$ in $z$-stack confocal images acquired at $2.5 \mu \mathrm{m}$ step size (30-40 stacks) using a $10 \times$ objective lens on a Zeiss LSM510 meta microscope. The $x, y$ coordinates corresponding to the center of each cell was exported to Excel. A line was fitted to the pial surface and the line function $(A x+B y+C=0)$ was determined using the $x, y$ coordinates of the end points of the fitted line. To determine the linear distance $(d)$ of each cell from the pial surface, the following equation was used:

$$
d=\frac{|A x+B y+C|}{\sqrt{A^{2+}+B^{2}}} .
$$

The cells were binned into $50 \mu \mathrm{m}$ distances away from the pial surface for each section and then averaged across sections for each experimental group. One slice from each mouse was used for this analysis $(n=20$ mice).

For calculation of L4 transfection percentage, the density of mCherryexpressing neurons in L4 (volume of 250-450 $\mu \mathrm{m}$ from pia, $200 \mu \mathrm{m}$ width, and $5 \mu \mathrm{m} z$-stack depth) was quantified. This value was compared with the published value of neuronal density in rodent V1 L4 $(86.6 \times$ $10^{3} / \mathrm{mm}^{3}$; data from Gabbott and Stewart, 1987).

Light-evoked $\mathrm{Sr}^{2+}$-mEPSCs and light-evoked EPSCs. Slices were transferred to a submersion-type recording chamber mounted on the fixed stage of an upright microscope (E600 FN; Nikon) with oblique infrared illumination. AMPAR-mediated EPSCs were isolated pharmacologically with $20 \mu \mathrm{M}$ bicuculline and $100 \mu \mathrm{M}$ DL-2-amino-5 phosphonopentanoic acid (DL-APV). These agents were added to modified ACSF containing 4 mм $\mathrm{MgCl}_{2}$ and $4 \mathrm{~mm} \mathrm{SrCl}_{2}$ with $0 \mathrm{~mm} \mathrm{CaCl}_{2}$, which was bubbled with $95 \% \mathrm{O}_{2} / 5 \% \mathrm{CO}_{2}$, maintained at $30 \pm 1{ }^{\circ} \mathrm{C}$, and perfused continually at a rate of $2 \mathrm{ml} / \mathrm{min}$. Slices were allowed to incubate in this solution for a minimum of $30 \mathrm{~min}$ before recording. Neurons were identified visually in L2/3 and L4 and patched using a whole-cell patch pipette with a tip resistance between 3 and $5 \mathrm{M} \Omega$, which was filled with internal solution containing the following (in mM): $130 \mathrm{Cs}$-gluconate, $8 \mathrm{KCl}, 1 \mathrm{EGTA}, 10$ HEPES, 4 ATP, and 5 QX-314, pH 7.4, 285-295 mOsm. Biocytin (1 $\mathrm{mg} / \mathrm{ml}$ ) was added to the internal solution for post hoc cell identification. ChR2 was activated using a $455 \mathrm{~nm}$ light-emitting diode (LED; ThorLabs DC2100) illuminated through a $40 \times$ objective lens, and controlled by a digital stimulator (Cygnus DG4000A). The minimal light intensity to elicit a reliable response was determined on a cell-by-cell basis with $5 \mathrm{~ms}$ duration remaining constant. Cells were held at $-80 \mathrm{mV}$ and recorded for a minimum of $10 \mathrm{~min}$; event analysis was performed using Mini Analysis software (Synaptosoft). Data were acquired every $10 \mathrm{~s}$ for a duration of $1200 \mathrm{~ms}$, which included a seal test pulse (100 ms duration), a $500 \mathrm{~ms}$ duration before LED illumination, and a $500 \mathrm{~ms}$ duration after LED illumination. A $400 \mathrm{~ms}$ window before LED was used for quantifying spontaneous desynchronized events (preLED) and a $400 \mathrm{~ms}$ window after a $50 \mathrm{~ms}$ delay from LED onset was used for quantifying LED-evoked desynchronized events (postLED). To calculate the average amplitude of light-evoked $\mathrm{Sr}^{2+}$-mEPSCs corresponding to LED evoked desynchronized events without spontaneous events, we used the following equation:

$$
\frac{\left(A_{\text {post }} \times F_{\text {post }}\right)-\left(A_{\text {pre }} \times F_{p r e}\right)}{\left(F_{p o s t}-F_{p r e}\right)},
$$

where $A_{\text {post }}$ is the average amplitude postLED, $F_{\text {post }}$ is the average frequency postLED, $A_{\text {pre }}$ is the amplitude preLED, and $F_{p r e}$ is the average frequency preLED.

For paired pulse light-evoked EPSCs, recordings were done in ACSF with normal $\mathrm{Ca}^{2+}(2.5 \mathrm{~mm})$ and $\mathrm{Mg}^{2+}(1.5 \mathrm{~mm})$. Next, $20 \mu \mathrm{M}$ bicuculline and $100 \mu \mathrm{M}$ DL-APV were added to isolate AMPAR responses pharmacologically. Whole-cell voltage-clamp recordings were done on pyramidal neurons in $\mathrm{L} 2 / 3$ of $\mathrm{A} 1$ at a holding potential of $-80 \mathrm{mV}$. ChR2 was activated at 5 or $10 \mathrm{~Hz}$ frequencies using a 455 $\mathrm{nm}$ LED illumination through a $40 \times$ objective lens ( $5 \mathrm{~ms}$ duration) with light intensity adjusted to elicit monosynaptic responses. Six traces from each cell were averaged to calculate the paired pulse ratio (PPR).

Recording of spontaneous mEPSCs. AMPAR-mediated mEPSCs were isolated pharmacologically with $1 \mu \mathrm{M}$ tetrodotoxin (TTX), $20 \mu \mathrm{M}$ bicuc- 
ulline, and $100 \mu \mathrm{M}$ DL-APV. These agents were added to ACSF bubbled with $95 \% \mathrm{O}_{2} / 5 \% \mathrm{CO}_{2}$ and maintained at $30 \pm 1^{\circ} \mathrm{C}$, which was continually perfused at a rate of $2 \mathrm{ml} / \mathrm{min}$. Principal neurons in L2/3 and L4 were patched using a whole-cell patch pipette with a tip resistance between 3 and $5 \mathrm{M} \Omega$, which was filled with internal solution containing the following (in mM): 130 Cs-gluconate, $8 \mathrm{KCl}, 1$ EGTA, 10 HEPES, $4 \mathrm{ATP}$, and 5 QX-314, pH 7.4, 285-295 mOsm. Recordings were initiated 2-3 min after cell break-in. Biocytin $(1 \mathrm{mg} / \mathrm{ml})$ was included in the internal solution to confirm morphology and location of recorded cells. An Axon patch-clamp amplifier 700B (Molecular Devices) was used for voltage-clamp recordings. Cells were held at $-80 \mathrm{mV}$ and the recorded mEPSC data were digitized at $10 \mathrm{kHz}$ by a data acquisition board (National Instruments) and acquired through Igor Pro software (WaveMetrics). Analysis of mEPSCs was done using the Mini Analysis Program (Synaptosoft) with threshold set at three times the RMS noise. Two hundred consecutive mEPSCs were analyzed for each cell. Cells with a negative correlation between rise time and amplitude, a series resistance $>25 \mathrm{M} \Omega$, input resistance $\leq 100 \mathrm{M} \Omega$, and RMS noise $>2$ were excluded from analysis. In addition, mEPSCs with rise time $>3 \mathrm{~ms}$ were excluded from analysis because they may reflect dendritic filtering.

Light-evoked $\mathrm{Sr}^{2+}$-mIPSCs. These events were recorded in a similar experimental setup to light-evoked $\mathrm{Sr}^{2+}$ mEPSCs with the following differences. The bath contained normal ACSF (described above) with 4 $\mathrm{mM} \mathrm{Sr}{ }^{2+}$ and $4 \mathrm{~mm} \mathrm{Mg}^{2+}$, but contained the following drugs to isolate IPSCs pharmacologically: $100 \mu \mathrm{M}$ DL-APV and $10 \mu \mathrm{M}$ NBQX. The internal solution contained the following (in $\mathrm{mm}$ ): $130 \mathrm{CsCl}, 8 \mathrm{KCl}, 1$ EGTA, 10 HEPES, 4 ATP, and 5 QX-314, pH 7.4, 285-295 mOsm. This internal solution produces a symmetrical $\mathrm{Cl}^{-}$gradient and thus allows recording of IPSCs as inward currents at $-80 \mathrm{mV}$ holding potential. Responses were acquired from each cell for a minimum of $10 \mathrm{~min}$ and LEDactivated responses were generated using minimal stimulation to produce a visible desynchronized release of vesicles. Analysis windows for preLED and postLED events were set the same as used for the $\mathrm{Sr}^{2+}$ mEPSC experiments. Because ChR2 activation is through LED illumination through a $40 \times$ objective lens (the same as in light-evoked $\mathrm{Sr}^{2+}$-mEPSC experiments) and PV-Cre expression is not laminar specific, we cannot determine the laminar source of PV inputs to the postsynaptic neuron.

Recording of spontaneous mIPSCs. mIPSCs were recorded in L2/3 and L4 of A1 in the presence of $1 \mu \mathrm{M}$ TTX, $100 \mu \mathrm{M}$ DL-APV, and $10 \mu \mathrm{M}$ NBQX, which were then analyzed using the Mini Analysis program (Synaptosoft). The intracellular solution used contained the following (in mM): $130 \mathrm{CsCl}, 8 \mathrm{KCl}, 1$ EGTA, 10 HEPES, 4 ATP, and 5 QX-314, pH 7.4, 285-295 mOsm. Cells were held at $-80 \mathrm{mV}$. Three hundred consecutive mIPSCs from each cell were selected for analysis, but bursts (characterized as $>2$ events with an interevent interval of $<10 \mathrm{~ms}$ ) were excluded from amplitude measurements. As with mEPSCs, cells with a negative correlation between rise time and amplitude, series resistance $>25 \mathrm{M} \Omega$, and input resistance $\leq 100 \mathrm{M} \Omega$ were excluded from analysis. Cells with rise times $>5 \mathrm{~ms}$ were also excluded.

Statistical analysis. Data are expressed as mean \pm SEM. One-factor ANOVA was used to analyze data across multiple groups, Student's $t$ test was used for two-group comparisons. For all tests, $p<0.05$ was considered statistically significant.

Biocytin processing. Three-hundred-micrometer-thick cortical slices were fixed in $4 \%$ paraformaldehyde overnight at $4^{\circ} \mathrm{C}$. Slices were rinsed $2 \times 10 \mathrm{~min}$ in $0.1 \mathrm{M}$ phosphate buffer $(\mathrm{PB})$ containing $19 \mathrm{~mm}$ $\mathrm{NaH}_{2} \mathrm{PO}_{4} \cdot \mathrm{H}_{2} \mathrm{O}$ and $81 \mathrm{~mm} \mathrm{Na} \mathrm{HPO}_{4}$ at room temperature and permeabilized in $2 \%$ Triton X-100 in $0.1 \mathrm{~mm}$ PB for $1 \mathrm{~h}$. Slices were then incubated in avidin-Alexa Fluor 633 or 488 conjugate diluted 1:2000 in $1 \%$ Triton X-100/0.1 M PB overnight at $4^{\circ} \mathrm{C}$ in the dark. After the incubation, slices were washed $2 \times 10 \mathrm{~min}$ in $0.1 \mathrm{M} \mathrm{PB}$, mounted on glass slides, and allowed to dry overnight in the dark. Slides were coverslipped with Prolong Anti-fade (Invitrogen) mounting medium and sealed with nail polish. Images were taken using a Zeiss LSM 510 META confocal microscope.

\section{Results}

Brief visual deprivation in adults cross-modally potentiates L4 to L2/3 synapses in A1

Previously, we reported that 1 week of visual deprivation in the form of DE potentiates thalamocortical synapses to L4 of A1 in adult mice (Petrus et al., 2014), which suggests that cross-modal sensory loss leads to strengthening of FF circuits. We investigated whether the next level of FF synapses, which are L4 synapses onto L2/3 neurons in A1, also undergo cross-modal plasticity after 1 week of DE (Fig. 1A). To study this, we specifically expressed ChR2 in L4 neurons using transgenic mice expressing Cre recombinase in L4 neurons (Scnn1a-Cre-Tg3, L4-Cre) and stereotatically injecting adeno-associated virus (AAV) containing double-floxed ChR2 (DIO-ChR2-mCherry) to L4 of A1 or V1. To verify that the expression of ChR2 is mainly limited to L4, we quantified ChR2-mCherry-expressing neurons across the depth of $\mathrm{A} 1$ or $\mathrm{V} 1$. We found that most of the expression was limited to between 300 and $500 \mu \mathrm{m}$ depth from pia, which approximately corresponds to L4 (Fig. $1 B$ ). To assess the strength of L4 synapses onto L2/3 pyramidal neurons, we performed whole-cell voltageclamp recordings of pharmacologically isolated AMPARmediated EPSCs evoked by activation of ChR2 via a brief pulse of blue LED ( $455 \mathrm{~nm}, 5 \mathrm{~ms}$ pulse duration). To quantify the strength of individual L4 synapses without complications from differential ChR2 expression levels or ChR2-expressing L4 neuronal density, we substituted extracellular $\mathrm{Ca}^{2+}$ with $4 \mathrm{mM} \mathrm{Sr}^{2+}$ to desynchoronize evoked release of vesicles (Gil et al., 1999; Petrus et al., 2014). We then performed quantal analysis of LED evoked $\mathrm{Sr}^{2+}$ desynchronized mEPSCs $\left(\mathrm{Sr}^{2+}\right.$-mEPSCs), which are mediated by single vesicles released from L4 terminals. We compared the average amplitude of $\mathrm{Sr}^{2+}$-mEPSCs from A1-L2/3 pyramidal neurons of control NR adult mice (P90) and those of adult mice that were DE for 1 week before the experiment. We found that 1 week of DE significantly increased the amplitude of light-evoked $\mathrm{Sr}^{2+}$-mEPSCs in A1-L2/3 neurons (Fig. 1C). There was no significant change in the PPR of light-evoked EPSCs measured using 100 and 200 ms ISIs (Fig. 1D). We verified that ChR2-expressing L4 neurons reliably fire action potentials at these intervals of light stimulation (Fig. 1E). These results suggest that loss of vision cross-modally potentiates the FF inputs from L4 to L2/3 in A1, which is mainly postsynaptic in nature and similar to the potentiation observed at the same inputs in barrel cortex after DE (Jitsuki et al., 2011).

\section{Brief visual deprivation in adults cross-modally depresses lateral inputs to $\mathrm{A} 1-\mathrm{L} 2 / 3$}

DE-induced potentiation of L4 to L2/3 synapses in A1 appears to conflict with our previous report in juveniles showing that $\mathrm{DE}$ decreases the amplitude of spontaneous mEPSCs in A1-L2/3 (Goel et al., 2006). To determine whether this apparent discrepancy is due to the age of the animals studied, we measured changes in spontaneous mEPSCs in the presence of TTX in adults with or without 1 week of DE. Consistent with our juvenile data, we found that 1 week of DE significantly decreased the average amplitude of spontaneous mEPSCs in A1-L2/3 neurons (Fig. $2 A)$. These results suggest that DE in adults potentiates $\mathrm{L} 4-\mathrm{L} 2 / 3$ synapses and decreases the amplitude of spontaneous mEPSCs in L2/3 neurons. Therefore, the discrepancy between spontaneous and evoked EPSCs might be due to differences in the subset of synapses sampled with each technique. It is estimated that L4 synapses comprise $\sim 5 \%$ of the total synapses onto L $2 / 3$ neurons (Binzegger et al., 2004). Therefore, we surmised that spontaneous mEPSCs may mainly reflect the more abundant intracortical syn- 
A

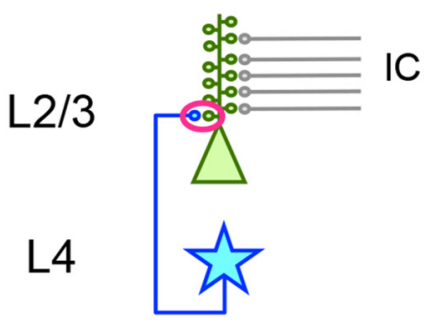

B

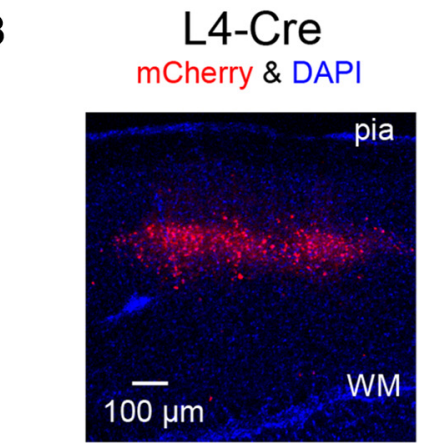

L4-Cre

mCherry \& DAPI

$100 \mu \mathrm{m}$
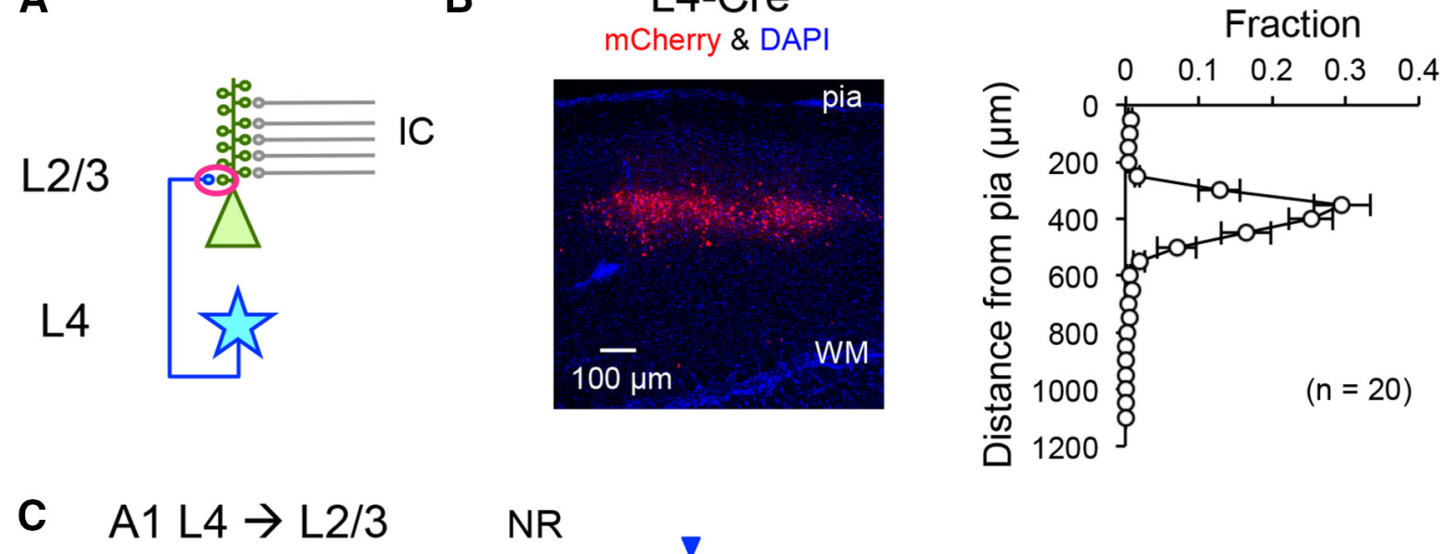

NR
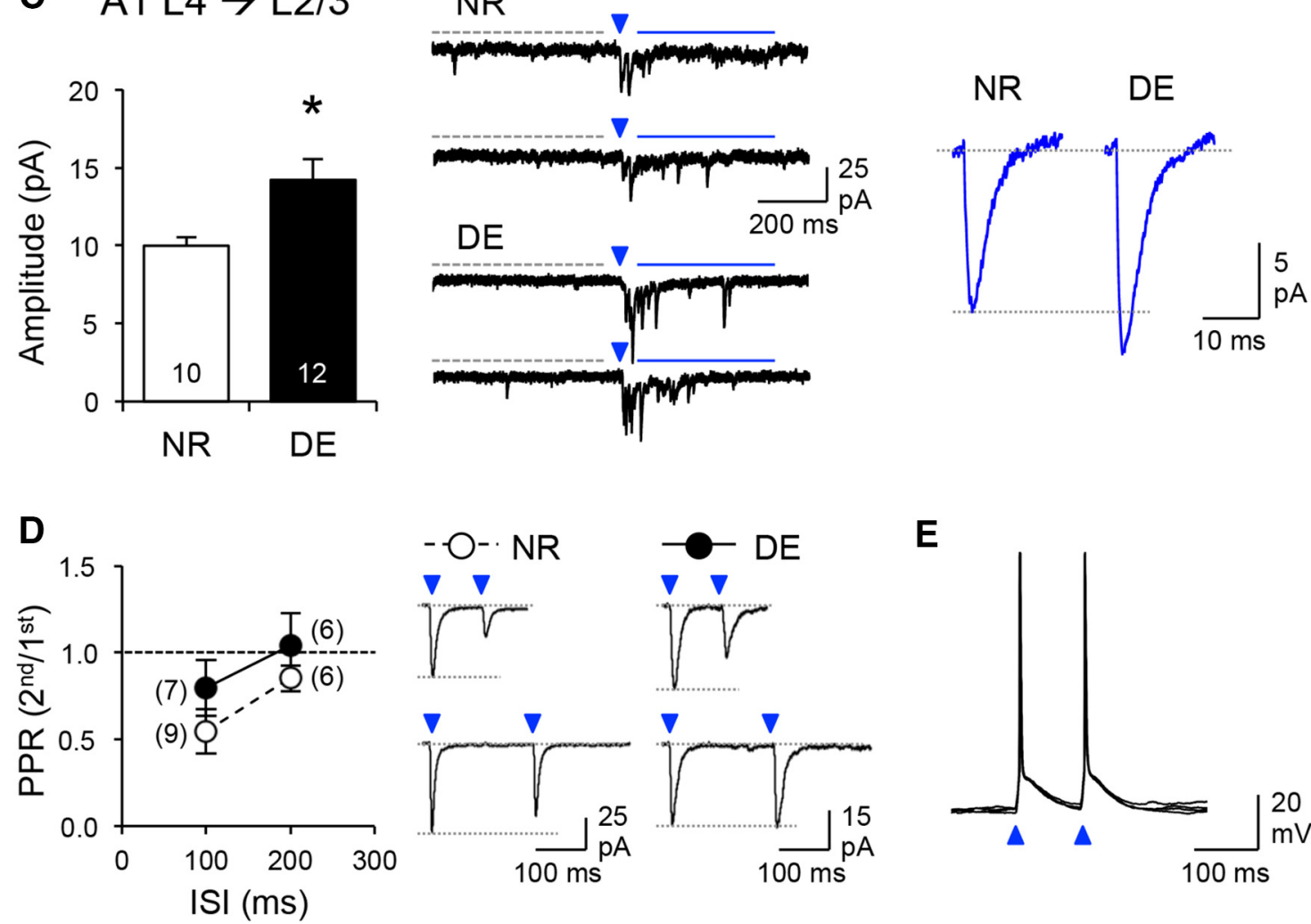

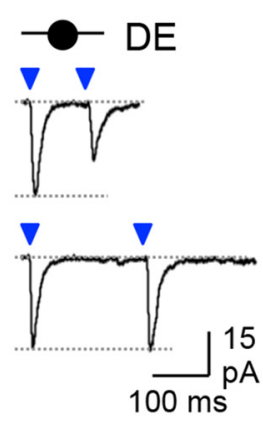

$\mathbf{E}$

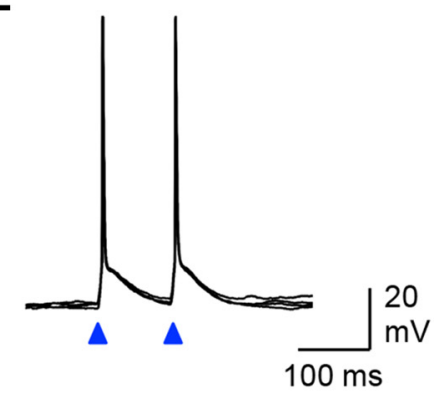

Figure 1. A1- $L 4$ synapses to $L 2 / 3$ are potentiated after 1 week of $D E$ in adults. $A$, Schematic diagram showing FF synaptic inputs from $A 1-L 4$ to $L 2 / 3$. B, Confirmation that $L 4-c r e$ mice injected with AAV-DI0-ChR2-mCherry (red) effectively restrict expression of ChR2 to L4. Left, Confocal image of V1 showing ChR2-mCherry expression in L4. The section was counterstained with DAPI (blue). Right, Quantification of the depth profile of ChR2-mCherry-expressing neurons. Twenty sections of both V1 and A1 were analyzed. The linear distance from pia was calculated as detailed in the Materials and Methods. The estimated transfection yield across analyzed sections was $17.4 \pm 2.0 \%$ of $L 4$ neurons (see Materials and Methods for details). C, Quantification of light-evoked $\mathrm{Sr}^{2+}$-mEPSCs recorded in A1-L2/3 pyramidal neurons. Left, There was a significant increase in the average amplitude of Sr ${ }^{2+}$-mEPSCs after 1 week of DE in adults (NR: $10.0 \pm 0.5 \mathrm{pA}, n=10$; DE: $14.2 \pm 1.4, n=12 ; t$ test: ${ }^{*} p=0.011$ ). Middle, Example traces from NR and DE groups. LED ( $455 \mathrm{~nm}, 5 \mathrm{~ms}$ duration) was shone at the time indicated with the blue downward arrowhead to activate $\mathrm{L} 4$ inputs. Light-evoked $\mathrm{Sr}^{2+}$-mEPSCs were analyzed during a time window depicted with the blue line, whereas spontaneous mEPSCs were quantified during a time window shown with gray dotted line before the LED stimulation. Right, Average traces of light-evoked $\mathrm{Sr}^{2+}$-mEPSCs after subtraction of spontaneous mEPSCs. See Materials and Methods for details of analysis. D, No significant change in PPR of light-evoked EPSCs in A1-L2/3 pyramidal neurons. Left, Only a trend of an increase in average PPR (calculated as amplitude of second EPSC divided by amplitude of first EPSC) in DE group (100 ms ISI: $t$ test, $p=0.25 ; 200 \mathrm{~ms}|S|: t$ test, $p=0.38$; number of cells in parenthesis). Right, Average light-evoked EPSC traces for $100 \mathrm{~ms}$ (top) and $200 \mathrm{~ms}$ (bottom) ISIs. Blue downward arrowheads indicate LED stimulation. E, ChR2-expressing L4 neurons can reliably generate action potentials with $100 \mathrm{~ms}$ ISI LED pulses (blue upward arrowheads). Overlay of four current-clamp traces are shown.

apses. To test this idea, we placed a stimulating electrode lateral to the recording site in $\mathrm{L} 2 / 3$ and measured $\mathrm{Sr}^{2+}$-mEPSCs evoked by electrical stimulation of $\mathrm{L} 2 / 3$ lateral inputs. We found that DE decreased the strength of A1-L2/3 lateral inputs (Fig. $2 B$ ), which mirrors the effects that we saw with spontaneous mEPSCs (Fig. $2 A)$. Collectively, our data suggest that mEPSCs recorded from A1-L2/3 mainly reflect lateral inputs to $\mathrm{L} 2 / 3$ and that DE poten- tiates FF inputs from L4 to L2/3 at the expense of lateral inputs from $\mathrm{L} 2 / 3$.

Brief visual deprivation in adults cross-modally potentiates recurrent inputs to $\mathrm{A} 1-\mathrm{L} 4$

We previously reported that FF input from the medial geniculate body to A1-L4 is potentiated in DE mice (Petrus et al., 2014). 

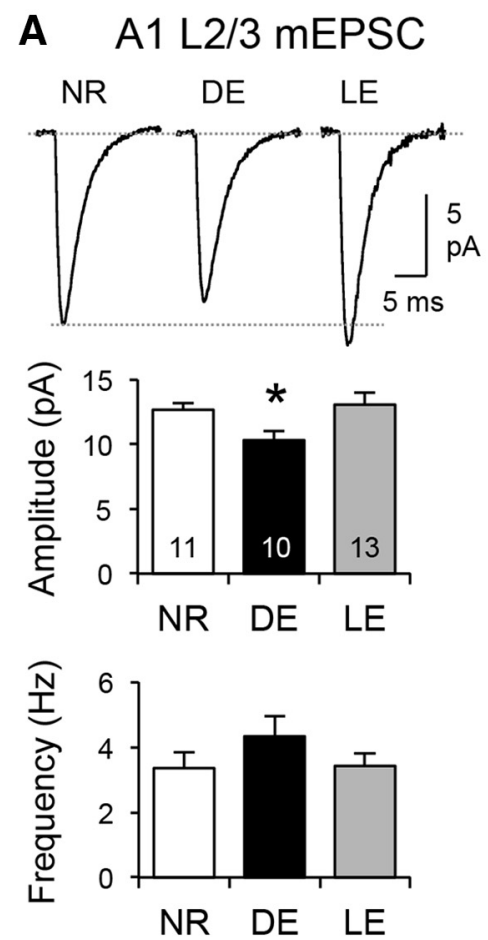

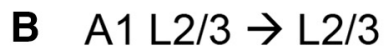

L2/3

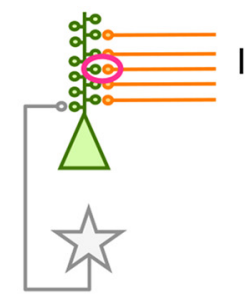

IC
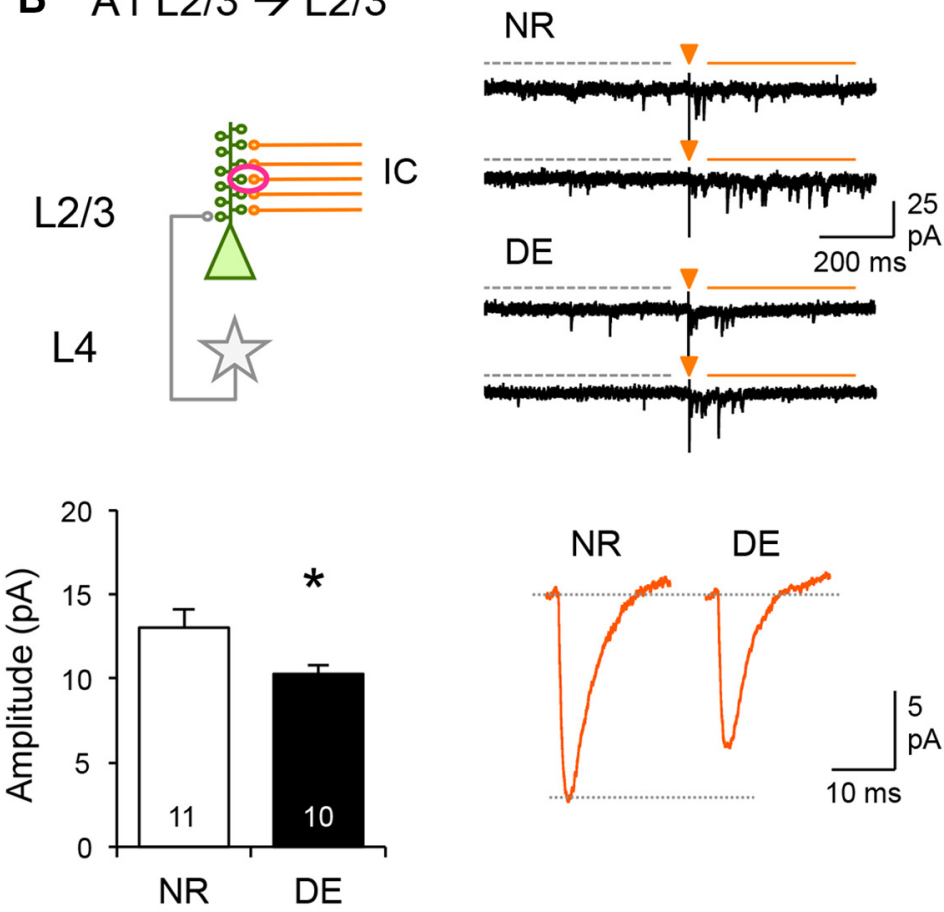

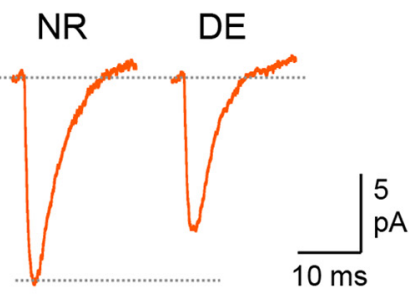

Figure 2. A1-L2/3 mEPSCs and lateral inputs to $A 1-L 2 / 3$ are weakened after 1 week of DE in adult mice. $A$, In adult mice, mEPSC amplitudes in $A 1-L 2 / 3$ reduced after 1 week of $D E$, which reversed after 1 week of light exposure (LE) (middle). There was no significant change in the mEPSC frequency across the groups (Bottom panel). See Table 1 for mEPSC parameters. Top, Average mEPSC traces from each group. $\boldsymbol{B}$, The strength of lateral inputs to A1-L2/3 also decreased with 1 week of DE in adult mice. Top left, Circuit diagram showing lateral intracortical (IC) inputs to A1-L2/3. Top right, Example traces of electrical stimulation-evoked $\mathrm{Sr}^{2+}$-mEPSCs from NR and 1 week DE groups. Orange downward arrowhead depicts the onset of stimulation through an electrode placed laterally in L2/3. Orange line shows the time window used for collecting electrical-stimulation-evoked Sr${ }^{2+}$-mEPSCs. Gray dotted line is the time window used for collecting spontaneous mEPSCs. Bottom left, Comparison of average electrical-stimulation-evoked Sr ${ }^{2+}$-mEPSCs (NR: $13.0 \pm 1.1 \mathrm{pA}, n=11 ; \mathrm{DE}: 10.3 \pm 0.5 \mathrm{pA}, n=10 ; t$ test: ${ }^{*} p=0.037$ ). Bottom right, Average traces of electrical-stimulation-evoked $\mathrm{Sr}^{2+}$-mEPSCS after subtraction of spontaneous mEPSCs.

There is evidence that the ability of L4 neurons to drive cortical activity may rely on recurrent excitatory lateral connections within the layer (Douglas et al., 1995; Stratford et al., 1996; Douglas and Martin, 2007; Liu et al., 2007; Li et al., 2013; but see Bruno and Sakmann, 2006). We therefore investigated whether DE cross-modally alters synaptic strength between L4 neurons in A1. To do this, we used the same optogenetics method to express ChR2 specifically in L4 neurons, but recorded from a neighboring non-ChR2-expressing L4 neuron (Fig. $3 A, B$ ). To measure quantitatively the strength of L4 synapses onto non-ChR2expressing L4 neurons, we measured the amplitude of lightevoked $\mathrm{Sr}^{2+}$-mEPSCs. We observed a significant increase in the amplitude of light-evoked $\mathrm{Sr}^{2+}$-mEPSCs in A1-L4 neurons after 1 week of DE (Fig. 3C,D), which suggests an increase in the strength of recurrent connections in A1-L4. Our results are consistent with the interpretation that the recurrent connections in L4 may amplify the FF signal arriving through thalamocortical inputs before its propagation to $\mathrm{L} 2 / 3$.

\section{Laminar-specific changes in inhibitory synaptic transmission in $\mathrm{A} 1$ after brief $\mathrm{DE}$}

The balance between excitatory and inhibitory synapses is thought to be critical for cortical function (Tao et al., 2014) and is often finely maintained across neurons (Xue et al., 2014). In addition, inhibition sharpens the tuning curves of sensory cortical neurons (Sillito, 1975; Crook and Eysel, 1992; Liu et al., 2011; Li et al., 2014) and provides temporal precision of neural responses (Wehr and Zador, 2003). Therefore, we examined whether cross-modal changes in inhibitory inputs to A1 accompanied our observed alterations in excitatory inputs. We targeted parvalbumin-positive $\left(\mathrm{PV}^{+}\right)$interneurons for our study because they constitute the majority of inhibitory neurons (Gonchar and Burkhalter, 1997; Rudy et al., 2011; Pfeffer et al., 2013), provide strong perisomatic inhibition to principal neurons (Chattopadhyaya et al., 2007), are readily regulated by sensory experience (Huang et al., 1999; Kuhlman et al., 2013; Gao et al., 2014), and mainly contribute to shaping the receptive field tuning of principal neurons (Li et al., 2014) or their input gain (Atallah et al., 2012). We targeted expression of ChR2 specifically in $\mathrm{PV}^{+}$interneurons using a PV-Cre line and stereotactically injected AAV-DIO-ChR2-mCherry in A1. We then recorded from principal neurons in L2/3 or L4 of A1 (Fig. 4) and measured light-evoked $\mathrm{Sr}^{2+}$-mIPSCs. We found that 1 week of DE significantly potentiated the amplitude of light-evoked $\mathrm{Sr}^{2+}$-mIPSCs in A1-L4 principal neurons (Fig. $4 A$ ). In contrast, there was no difference in light-evoked $\mathrm{Sr}^{2+}$-mIPSCs in $\mathrm{A} 1-\mathrm{L} 2 / 3$ principal neurons between NR and DE mice (Fig. 4B), suggesting that DE specifically strengthens evoked inhibition from $\mathrm{PV}^{+}$interneurons to L4 of A1.

In contrast to the evoked IPSCs from $\mathrm{PV}^{+}$interneurons, we did not observe changes in the amplitude of spontaneous miniature IPSCs (mIPSCs) in L4 or L2/3 of A1 after DE (Fig. 5). DE also did not alter the frequency of mIPSCs in A1-L4 (Fig. 5A), but significantly increased the frequency of mIPSCs recorded from A1-L2/3 pyramidal neurons (Fig. 5B). There was no significant change in the kinetics of mIPSCs in either layer after DE (Table 1). 
A

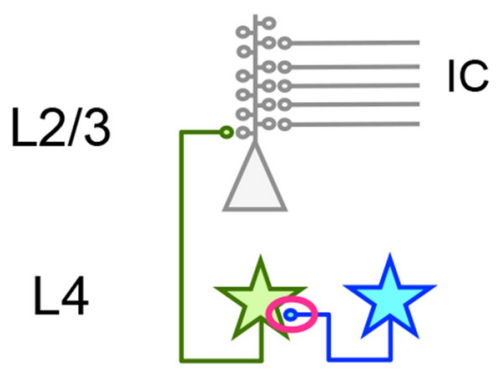

\section{C $\quad \mathrm{A} 1 \mathrm{~L} 4 \rightarrow \mathrm{L} 4$}

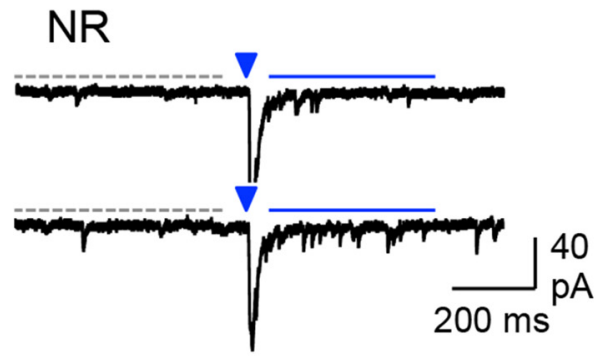

\section{D $\quad \mathrm{A} 1 \mathrm{~L} 4 \rightarrow \mathrm{L} 4$}
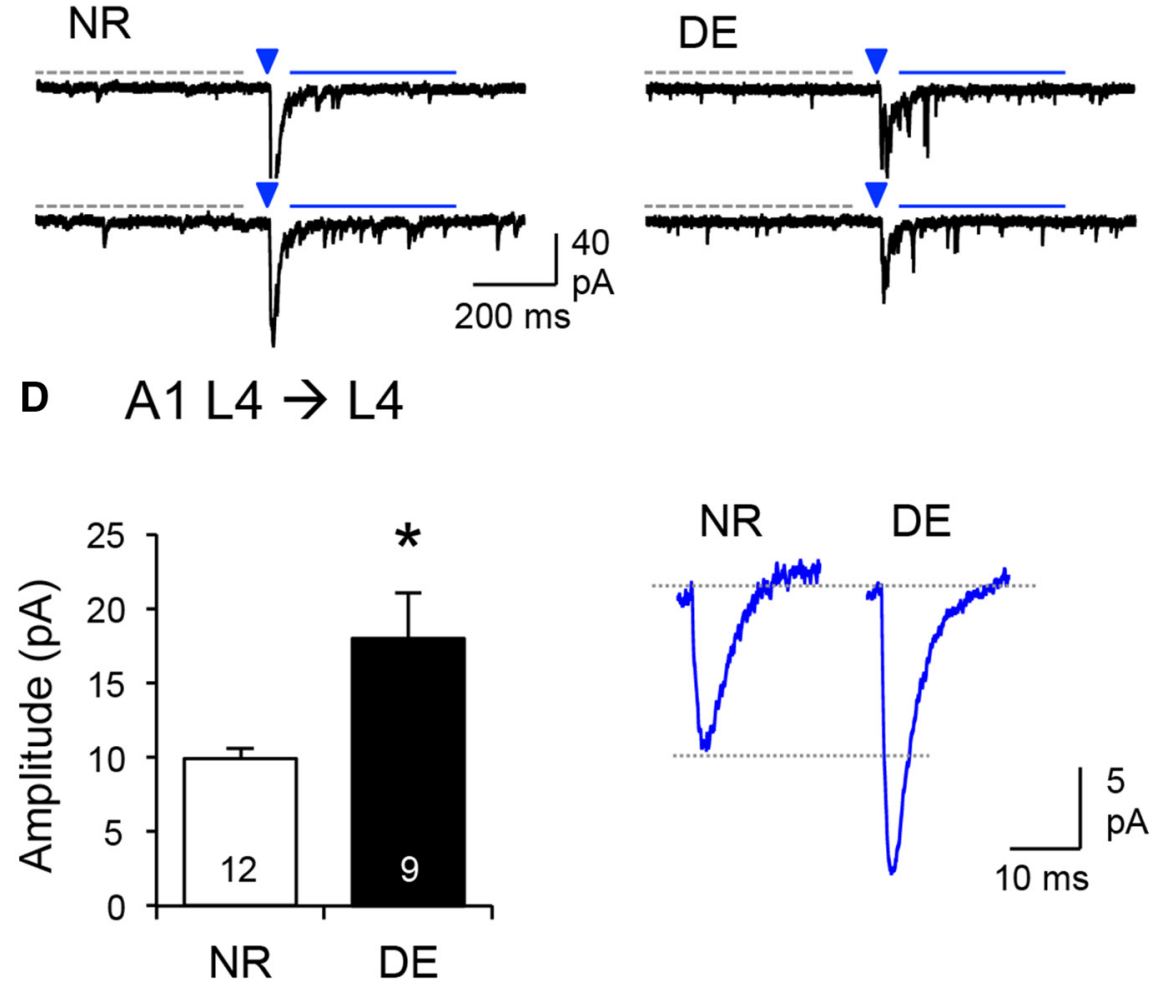

Figure 3. Recurrent excitatory synapses between $A 1-L 4$ neuron potentiation after 1 week of $D E$ in adults. $A$, Schematic showing recurrent excitatory inputs between $A 1-L 4$ neurons. $B, A$ non-ChR2-expressing neuron (green) filled with biocytin present in the recording pipette is situated next to ChR2-expressing neurons (red) in A1-L4. The section was counterstained with DAPI (blue). C, Representative traces of light-evoked $\mathrm{Sr}^{2+}$-mEPSCs recorded from non-ChR2-expressing A1-L4 neurons. LED stimulation was given at the time point indicated with a blue downward arrowhead. Light-evoked $\mathrm{Sr}^{2+}$-mEPSCs were collected during a time window shown in blue line. Spontaneous mEPSCs were collected during a window before the LED stimulation (gray dotted line). $\boldsymbol{D}$, Left, Comparison of average light-evoked Sr${ }^{2+}$-mEPSCs (NR: $9.9 \pm 0.7 \mathrm{pA}, n=12 ; \mathrm{DE}: 18.0 \pm 3.1 \mathrm{pA}, n=9 ; t$ test: $\left.{ }^{*} p=0.031\right)$. Right, Average light-evoked $\mathrm{Sr}^{2+}{ }_{-} \mathrm{mEPSC}$ after subtraction of spontaneous mEPSCS.

In summary, we observed dissociation between regulation of evoked IPSCs from $\mathrm{PV}^{+}$interneurons and mIPSCs in both layers of A1. DE specifically potentiated PV-evoked IPSCs without changes in mIPSCs in L4, whereas it specifically increased the frequency of mIPSCs without changes in MIPSC amplitude or PV-evoked IPSCs in L2/3. These results suggest that evoked IPSCs and mIPSCs may be independently regulated by cross-modal plasticity. We cannot rule out the possibility that mIPSCs may reflect inhibitory inputs from other types of interneurons, but $\mathrm{PV}^{+}$interneurons provide strong perisomatic inhibition and our use of a rise-time cutoff for mIPSC analysis (see Materials and Methods for details) should bias our sampling toward mIPSCs from $\mathrm{PV}^{+}$interneurons.
Brief visual deprivation in adults potentiates lateral inputs to $\mathrm{L} 2 / 3$ in $\mathrm{V} 1$ We showed previously that visual deprivation also alters V1 synapses in addition to triggering cross-modal adaptation in A1 (Goel et al., 2006; He et al., 2012; Petrus et al., 2014). To determine whether brief DE in adults also alters the FF circuitry in $\mathrm{V} 1$, we injected AAV-DIOChR2-mCherry into V1-L4 of L4-Cre mice and measured the amplitude of light-evoked $\mathrm{Sr}^{2+}$-mEPSCs recorded in V1-L2/3 pyramidal neurons. In contrast to $A 1$, we found that 1 week of DE failed to increase the strength of FF synapses from L4 to L2/3 in V1 (Fig. 6A). Previous studies in juveniles demonstrated that $\mathrm{DE}$ increases the average amplitude of spontaneous mEPSCs in L2/3 of V1 (Desai et al., 2002; Goel et al., 2006; Goel and Lee, 2007; Gao et al., 2010; Goel et al., 2011; He et al., 2012; Petrus and Lee, 2014). We confirmed that this is also the case in P90 adults (Fig. 6B). Similar to what we demonstrated in $\mathrm{A} 1$, we found that spontaneous mEPSCs in L2/3 of V1 mainly reflect lateral inputs, because $\mathrm{Sr}^{2+}$-mEPSCs evoked by electrically stimulating the lateral inputs to $\mathrm{L} 2 / 3$ pyramidal neurons also potentiated after DE (Fig. 6C). Together with our previous results showing no change in thalamocortical synaptic strength in L4 of V1 after DE (Petrus et al., 2014), our present results suggest that visual deprivation mainly potentiates lateral inputs to $L 2 / 3$ of $V 1$ without changes in the strength of FF connections.

We recently reported that, in juveniles $(<$ P35), brief DE does not alter mIPSC amplitude, but specifically decreases mIPSC frequency (Gao et al., 2010; Gao et al., 2014). To determine whether brief DE alters evoked IPSCs from $\mathrm{PV}^{+}$interneurons in adult $\mathrm{V} 1$, we expressed ChR2 into $\mathrm{PV}^{+}$interneurons in $\mathrm{V} 1$ using $\mathrm{PV}-\mathrm{Cre}$ mice. We did not observe significant changes in the amplitude of light-evoked $\mathrm{Sr}^{2+}$-mIPSCs recorded from L4 principal neurons (Fig. 7A) or L2/3 pyramidal neurons (Fig. $7 B$ ). These results are consistent with previous studies reporting that visual deprivation in rodents does not change evoked IPSCs in V1-L4 (Jiang et al., 2010a) and limited inhibitory synaptic plasticity in V1-L2/3 during the critical period (<P35) (Morales et al., 2002; Jiang et al., 2010b).

\section{Discussion}

We found that a brief duration of DE cross-modally potentiates the FF excitatory synapses from L4 to L2/3 in A1 (Fig. 8A). This was accompanied by potentiation of recurrent excitatory synapses in L4 and depression of excitatory lateral synapses in L2/3. DE also cross-modally potentiates inhibitory synaptic transmission of A1 in both L4 and L2/3, but via distinct mechanisms. In L4, evoked IPSCs from $\mathrm{PV}^{+}$interneurons potentiates without 
changes in mIPSCs, whereas in L2/3, there was an increase in the frequency of mIPSCs without changes in PV-evoked IPSCs. In parallel, DE produced plasticity in V1, which involved potentiation of lateral inputs to L2/3 without changes in FF inputs or PV-evoked IPSCs (Fig. $8 B$ ). These results suggest that loss of vision in adults produces widespread input-specific plasticity to promote FF sensory processing in the A1 circuitry and intracortical processing in V1.

\section{Cross-modal adaptation of A1 excitatory circuits}

We reported previously that brief DE in adults induces cross-modal potentiation of FF TC inputs to A1-L4 (Petrus et al., 2014). Here, we demonstrated that recurrent excitatory synapses in A1-L4 also potentiate (Fig. 3), which is consistent with the idea that the recurrent circuit in L4 may amplify information arriving from TC synapses (Douglas et al., 1995; Stratford et al., 1996; Douglas and Martin, 2007; Liu et al., 2007; Li et al., 2013). Considering that recurrent excitatory connections in L4 contributes more significantly to the characteristic frequency (CF) tuning of these neurons (Liu et al., 2007) and linearly amplifies TC responses ( $\mathrm{Li}$ et al., 2013), potentiation of their synaptic strength may be responsible for the enhanced CF tuning of A1-L4 neurons after DE (Petrus et al., 2014).

We also found that the next-level FF excitatory synapses in A1, from L4 to L2/3, potentiate with DE (Fig. 1), suggesting that the amplified sensory signal in L4 may trigger LTP-like potentiation of L4L2/3 synapses. Potentiation of L4-L2/3 inputs has been reported in S1BF after binocular deprivation, which accompanied synaptic accumulation of AMPARs and occlusion of LTP (Jitsuki et al., 2011). A similar mechanism of AMPAR regulation is likely in A1, considering that the changes that we see are mostly in postsynaptic parameters (Fig. 1). The potentiation of L4 inputs to L2/3 contradicted our initial finding that DE cross-modally decreases the amplitude of mEPSCs recorded from A1 and S1BF L2/3 neurons (Goel et al., 2006; He et al., 2012). We report here that mEPSCs in L2/3 mainly reflects intracortical lateral inputs (Fig. 2), which constitute the majority of excitatory synapses to these neurons (Binzegger et al., 2004; Douglas and Martin, 2007). We previously interpreted that the cross-modal decrease in mEPSC amplitude in A1 and S1BF after DE is likely homeostatic synaptic plasticity (Goel et al.,

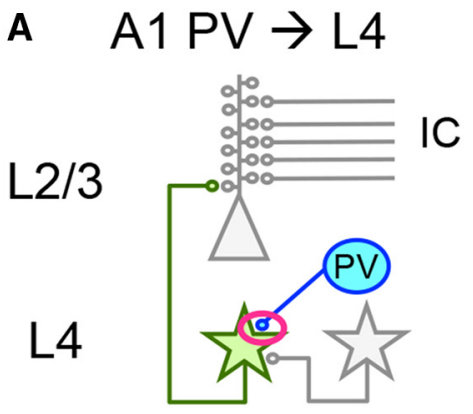

Biocytin/mCherry/DAPI
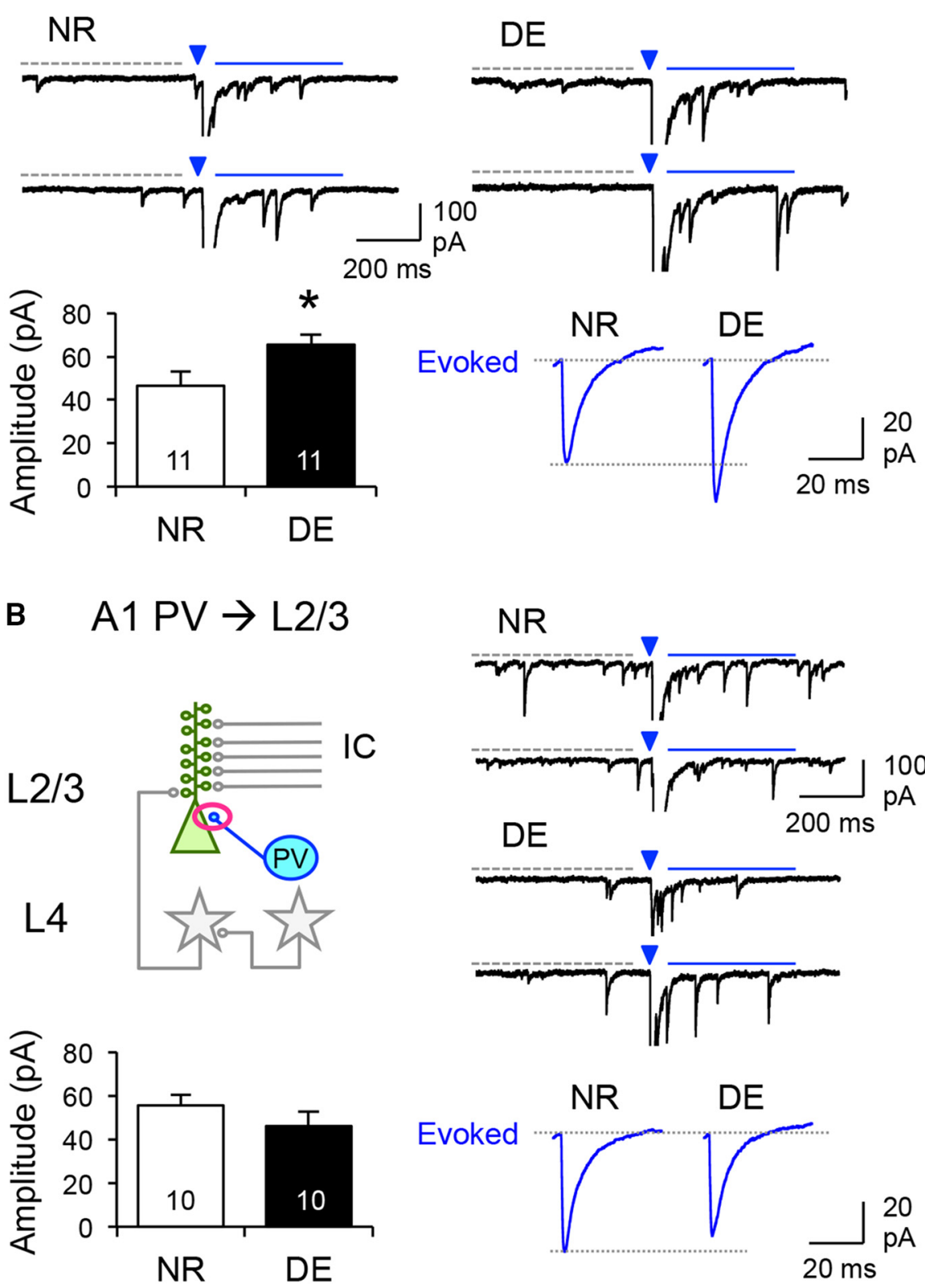

Figure 4. DE induces potentiation of $\mathrm{Sr}^{2+}$-mIPSCs evoked from $\mathrm{PV}^{+}$interneurons to $\mathrm{A} 1-\mathrm{L} 4$ principal cells, but does not alter their strength to $\mathrm{A} 1-\mathrm{L} 2 / 3$ pyramidal neurons. $A$, Potentiation of $\mathrm{PV}{ }^{+}$synapses to $\mathrm{A} 1-\mathrm{L} 4$ neurons after $\mathrm{DE}$. ChR2 was specifically expressed in $\mathrm{PV}^{+}{ }^{+}$interneurons by injecting AAV-DI0-ChR2 into PV-Cre mice. Top left, Schematic showing PV ${ }^{+}$inputs onto A1-L4 neurons. Top right, A biocytin-filled A1-L4 neuron (green) near $\mathrm{PV}^{+}{ }^{+}$interneurons expressing ChR2 (red) with DAPI counterstain (blue). Middle, Example light-evoked $\mathrm{Sr}^{2+}{ }^{-}$-mIPSCs from ChR-expressing $\mathrm{PV}^{+}$interneurons to A1-L4 principal neurons. Notations are same as in other figures. Bottom left, Comparison of average light-evoked Sr ${ }^{2+}{ }_{-} \mathrm{mIPSCs}$ (NR: $46.5 \pm 6.6 \mathrm{pA}, n=11 ; \mathrm{DE}: 65.6 \pm$ $4.7 \mathrm{pA}, n=11 ; t$ test: ${ }^{*} p=0.031$ ). Bottom right, Average light-evoked Sr ${ }^{2+}$-mIPSC traces after subtraction of spontaneous mIPSCS (see Materials and Methods for details). $\boldsymbol{B}$, No significant change in the strength of $\mathrm{PV}^{+}$synapses to A1-L2/3 neurons. Top left, Diagram showing $\mathrm{PV}^{+}$inputs onto A1-L2/3 neurons. Top right, Example traces of light-evoked Sr ${ }^{2+}$-mIPSCsfrom PV ${ }^{+}$interneurons. Bottom left, Comparison of average light-evoked Sr ${ }^{2+}$-mIPSCS (NR: $55.6 \pm 4.9 \mathrm{pA}, n=10 ; \mathrm{DE}: 46.1 \pm 6.8 \mathrm{pA}, n=10 ; t$ test: $p=0.275$ ). Bottom right, Average light-evoked $\mathrm{Sr}^{2+}$-mIPSC traces after subtraction of spontaneous mIPSCs. 
A $\quad$ A1 L4 mIPSC NR DE
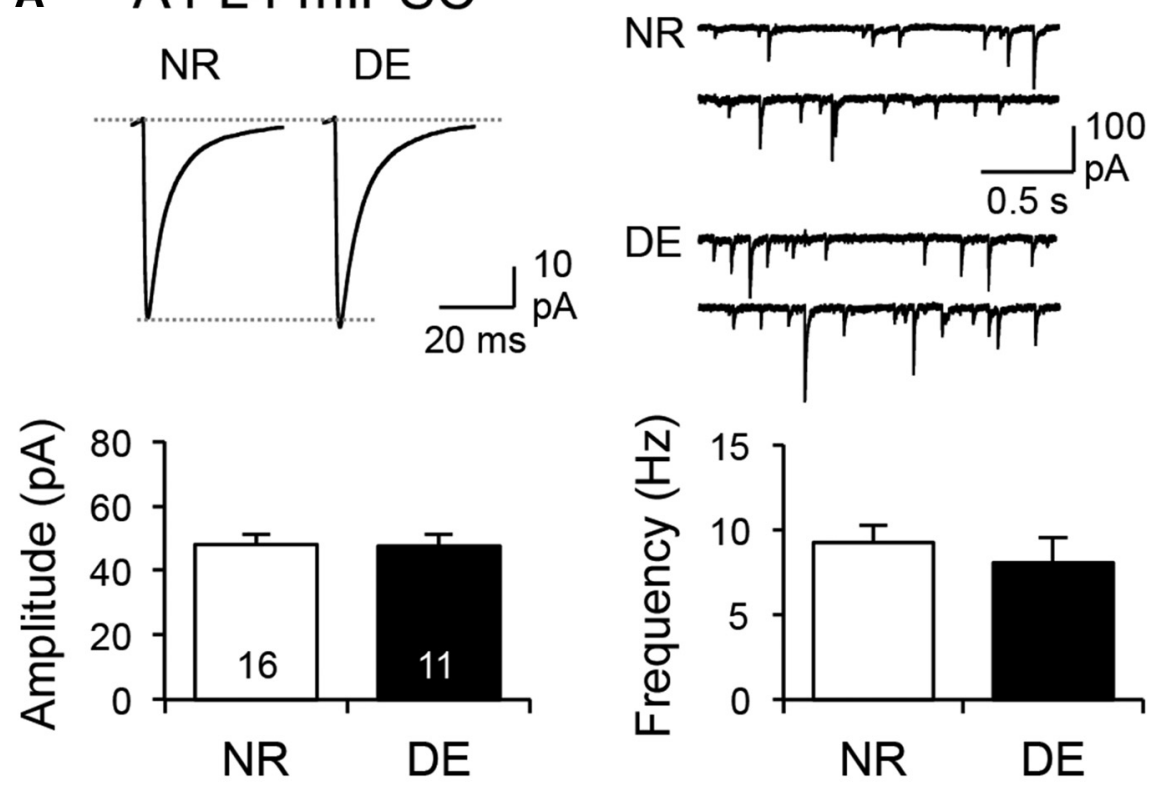

B A1 L2/3 mIPSC
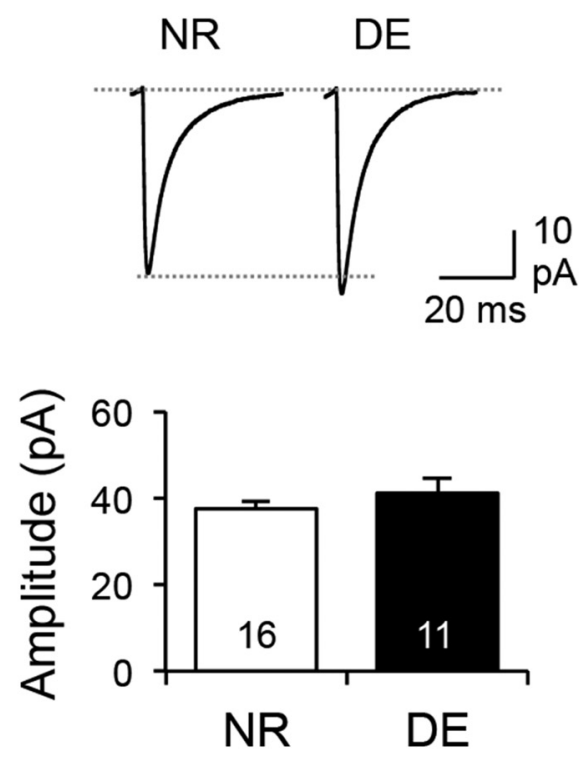
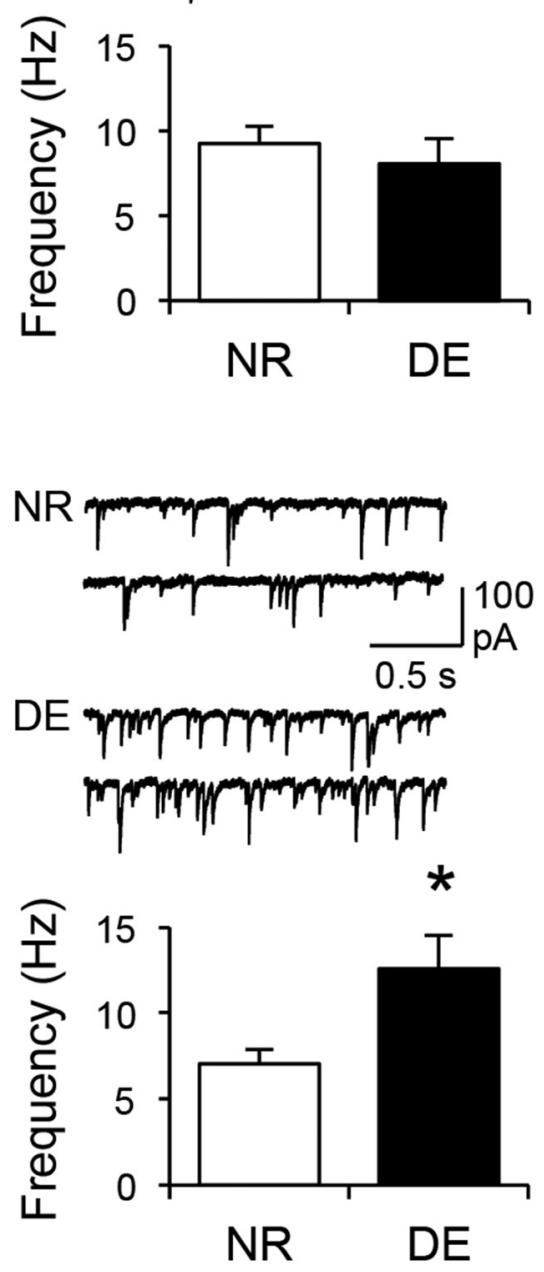

Figure 5. DE does not alter mIPSCs in $A 1-L 4$, but increases mIPSC frequency in A1-L2/3 principal neurons. $A$, Top left, Average mIPSC traces recorded from A1-L4 principal neurons in NR and DE mice. Top right, Example mIPSC traces from two groups. There was no significant change in mIPSC amplitude (bottom left) or frequency (bottom right) in A1-L4 neurons after DE. B, Top left, Average mIPSC traces recorded from A1-L2/3 principal neurons. Top right, Example mIPSC traces. There was no significant change in mIPSC amplitude (bottom left), but a significant increase in mIPSC frequency (bottom right) after DE. See Table 1 for mIPSC parameters.

2006; He et al., 2012; Whitt et al., 2014). Based on our new data, we suggest that the DE-induced reduction in A1-L2/3 lateral input strength may be a homeostatic adaptation to stronger FF drive from L4 neurons. A1-L2/3 neurons further process auditory signals as they arrive from thalamorecipient L4 (Winkowski and Kanold, 2013). Cross-modal downregulation of intralaminar synapses in A1-L2/3 is expected to affect intracortical processing. Together with the strengthening of FF excitatory synapses, this suggests that the mode of A1-L2/3 processing would shift from intracortical to FF after visual deprivation.
Cross-modal adaptation of A1 inhibitory circuits

Inhibitory circuitry is responsible for sharpening the functional tuning of primary sensory cortical neurons (Liu et al., 2011; Li et al., 2014). We found that DE cross-modally increases inhibition in both $\mathrm{L} 4$ and $\mathrm{L} 2 / 3$ of A1 via distinct mechanisms (Figs. 4, 5). We found potentiation of evoked IPSCs from $\mathrm{PV}^{+}$interneurons without changes in mIPSCs in A1-L4, but only mIPSC frequency was increased in A1-L2/3. The specific potentiation of $\mathrm{PV}^{+}$-IPSCs in A1-L4 is of interest in light of a recent report showing that $\mathrm{PV}^{+}$ interneuron-mediated inhibition is exquisitely balanced to the strength of excitatory synapses in each principal neuron (Xue et al., 2014). Therefore, potentiation of $\mathrm{PV}^{+}$-IPSCs may reflect this process to match inhibitory strength to the potentiation of TC and recurrent excitatory synapses on A1-L4 neurons after DE. The lack of a change in $\mathrm{PV}^{+}$-IPSCs in $\mathrm{A} 1-\mathrm{L} 2 / 3$ may then be due to the opposite regulation of excitatory FF and intracortical synaptic strengths, which may not produce a net increase in the overall excitatory synaptic strength. Regardless of the reason, the specific potentiation of $\mathrm{PV}^{+}$-IPSCs in A1-L4 of DE mice is expected to have functional consequences for L4 processing. $\mathrm{PV}^{+}$-interneurons mediate the majority of strong perisomatic inhibition, which is delayed with respect to excitatory synaptic transmission to provide temporal precision of postsynaptic action potential firing (Wehr and Zador, 2003; Zhang et al., 2011). Therefore, we surmise that cross-modal potentiation of $\mathrm{PV}^{+}$-IPSCs would increase spike precision, which may underlie enhanced processing of auditory information in A1-L4 neurons after vision loss (Petrus et al., 2014). Increased inhibition is also expected to narrow the tuning properties and thus may account for the sharper CF tuning of A1-L4 neurons seen in DE mice (Petrus et al., 2014).

We found a dissociation between the regulation of evoked IPSCs from $\mathrm{PV}^{+}$interneurons and mIPSCs in A1 (Figs. 4, 5). Although we cannot rule out the possibility that this may stem from contribution of other inhibitory neuronal types to mIPSCs, our results suggest that two modes of inhibitory synaptic transmission (i.e., evoked IPSCs and mIPSCs) may be independently regulated by sensory experience. This is not an isolated case: visual deprivation during the critical period has been shown to specifically prevent the developmental increase in the strength of evoked inhibition without changes in mIPSC amplitudes in V1 (Morales et al., 2002). The laminarspecific changes in inhibition observed in A1 after DE may be due 
Table 1. Parameters of mEPSCs and mIPSCs

\begin{tabular}{|c|c|c|c|c|c|c|c|c|c|c|}
\hline Area & Layer & Group & $n$ & Amplitude (pA) & Frequency $(\mathrm{Hz})$ & Rise time (ms) & Decay $\tau(\mathrm{ms})$ & Series $R(M \Omega)$ & Input $R(M \Omega)$ & $\overline{\text { RMS noise }}$ \\
\hline \multirow[t]{7}{*}{$\mathrm{A} 1$} & \multirow[t]{3}{*}{$\mathrm{L} 2 / 3 \mathrm{mEPSCs}$} & NR & 11 & $12.7 \pm 0.6$ & $3.4 \pm 0.5$ & $1.6 \pm 0.04$ & $2.9 \pm 0.2$ & $23 \pm 0.7$ & $274 \pm 44$ & $1.6 \pm 0.07$ \\
\hline & & $\mathrm{DE}$ & 10 & $10.3 \pm 0.7^{*}$ & $4.3 \pm 0.6$ & $1.7 \pm 0.04$ & $3.2 \pm 0.1$ & $22 \pm 1.2$ & $236 \pm 46$ & $1.7 \pm 0.04$ \\
\hline & & $\mathrm{LE}$ & 13 & $13.1 \pm 0.9$ & $3.4 \pm 0.4$ & $1.7 \pm 0.04$ & $2.7 \pm 0.1$ & $21 \pm 1.0$ & $229 \pm 42$ & $1.8 \pm 0.03$ \\
\hline & \multirow[t]{2}{*}{ L2/3 mlPSCs } & NR & 16 & $38 \pm 1.9$ & $7.1 \pm 0.8$ & $1.6 \pm 0.1$ & $6.4 \pm 0.5$ & $20 \pm 0.8$ & $215 \pm 19$ & $2.6 \pm 0.1$ \\
\hline & & $\mathrm{DE}$ & 11 & $41 \pm 3.3$ & $12.6 \pm 1.9^{*}$ & $1.7 \pm 0.1$ & $5.9 \pm 0.5$ & $19 \pm 1.1$ & $190 \pm 15$ & $2.5 \pm 0.1$ \\
\hline & \multirow[t]{2}{*}{ L4 mlPSCs } & NR & 16 & $48 \pm 3.2$ & $9.1 \pm 0.9$ & $1.2 \pm 0.1$ & $6.8 \pm 0.5$ & $20 \pm 0.7$ & $287 \pm 34$ & $2.6 \pm 0.1$ \\
\hline & & $\mathrm{DE}$ & 11 & $48 \pm 3.6$ & $8.1 \pm 1.5$ & $1.4 \pm 0.1$ & $7.2 \pm 0.8$ & $21 \pm 0.6$ & $327 \pm 57$ & $2.6 \pm 0.2$ \\
\hline \multirow[t]{3}{*}{ V1 } & \multirow[t]{3}{*}{$\mathrm{L} 2 / 3 \mathrm{mEPSCs}$} & NR & 14 & $10.3 \pm 0.3$ & $3.4 \pm 0.5$ & $1.7 \pm 0.05$ & $3.3 \pm 0.2$ & $22 \pm 0.8$ & $225 \pm 31$ & $1.7 \pm 0.04$ \\
\hline & & $\mathrm{DE}$ & 11 & $11.3 \pm 0.2^{*}$ & $2.6 \pm 0.4$ & $1.7 \pm 0.03$ & $3.3 \pm 0.1$ & $22 \pm 0.8$ & $188 \pm 24$ & $1.6 \pm 0.04$ \\
\hline & & $\mathrm{LE}$ & 10 & $9.8 \pm 0.4$ & $3.2 \pm 0.4$ & $1.5 \pm 0.09^{*}$ & $2.5 \pm 0.1^{*}$ & $22 \pm 0.9$ & $254 \pm 43$ & $1.6 \pm 0.07$ \\
\hline
\end{tabular}

*Statistically significant difference from corresponding NR. $p<0.05$ for one-factor ANOVA followed by Fisher's PLSD post hoc test for three group measurements, Student's $t$ test for two group measurements. $n=$ number of cells, $2-3$ slices per animal, $4-6$ animals per group; maximum of 3 cells per animal were used, maximum of 2 cells per slice.
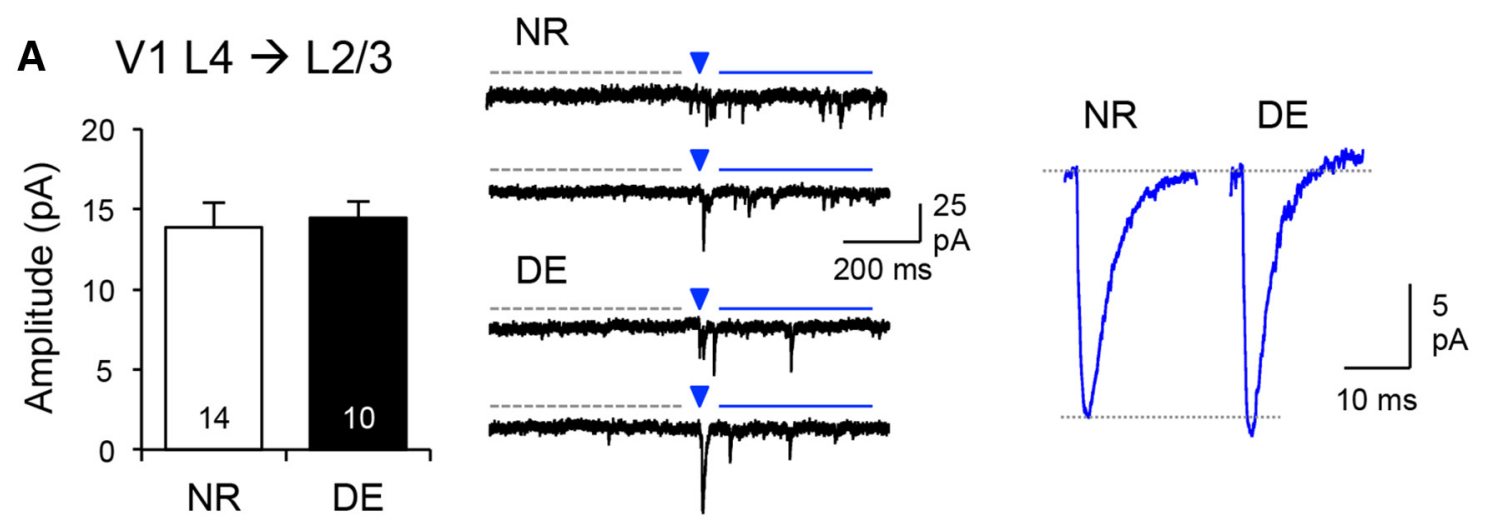

\section{B V1 L2/3 mEPSC}
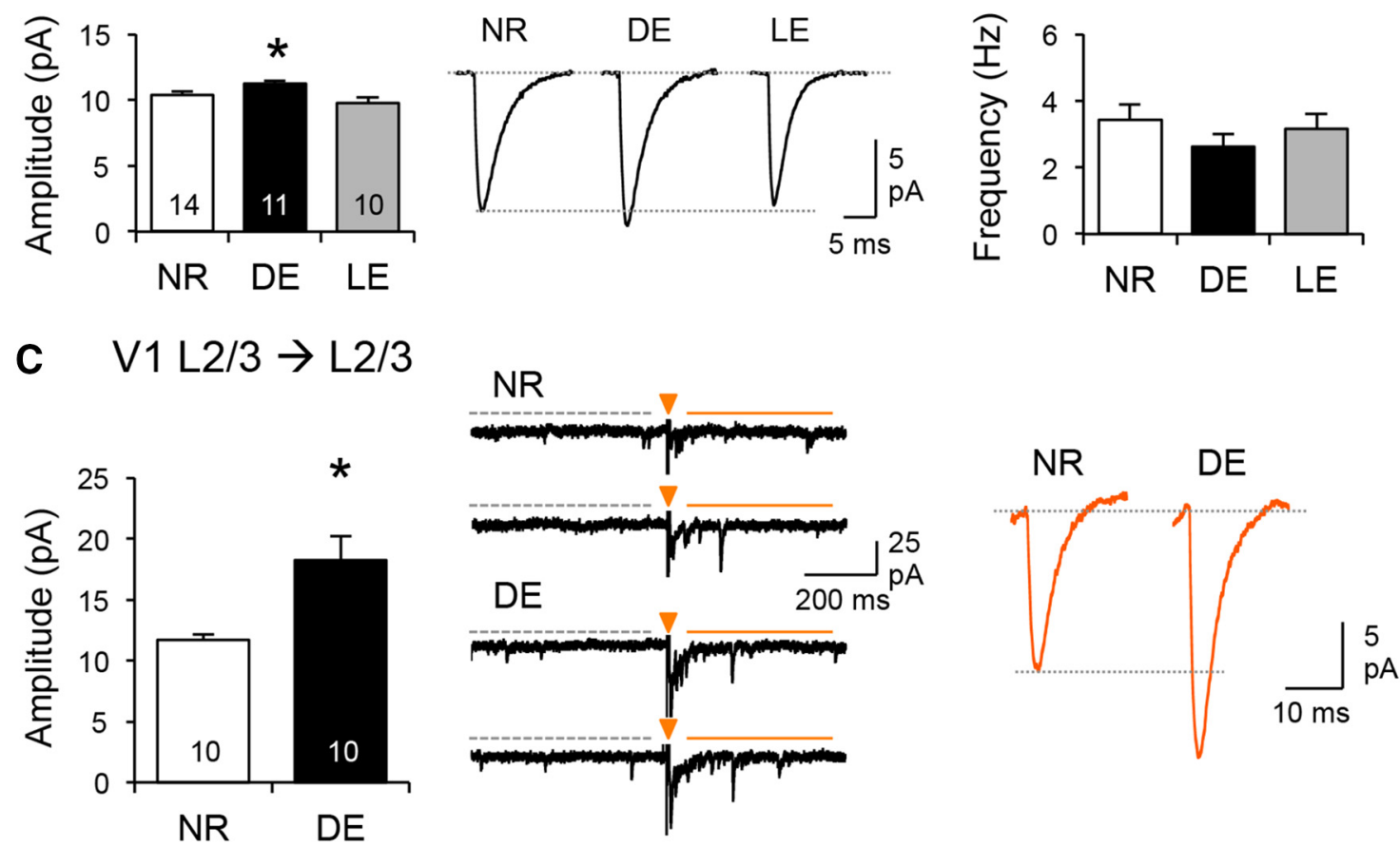

Figure 6. One week of DE in adults does not alter FF inputs to V1-L2/3 neurons, but potentiates their lateral inputs and mEPSC amplitudes. A, FF projections from V1-L4 to V-L2/3 neurons are not significantly different after DE. AAV-DI0-ChR2 was expressed in V1-L4 neurons using L4-Cre mice as described in the text. Left, Comparison of average light-evoked Sr ${ }^{2+}$-mEPSCs (NR: $13.9 \pm$ $1.6 \mathrm{pA}, n=14 ; \mathrm{DE}: 14.5 \pm 1.1 \mathrm{pA}, n=10 ; t$ test: $p=0.76$ ). Middle, Example traces of light-evoked Sr${ }^{2+}$-mEPSCs. Notations are the same as Figure 1C and Figure 3C. Right, Average light-evoked $\mathrm{Sr}^{2+}$-mEPSCs after subtraction of spontaneous mEPSCS. B, Left, Average amplitude of $\mathrm{mEPSC}$ in V1-L2/3 neurons potentiates after DE and reverses with 1 week of LE. Middle, Average $\mathrm{mEPSC}$ traces. Right, No significant change in mEPSC frequency in V1-L2/3 across the groups is seen. See Table 1 for mEPSC parameters. C, Lateral intracortical inputs to V1-L2/3 potentiates after DE. Left, Comparison of average evoked $\mathrm{Sr}^{2+}{ }^{-m E P S C}$ collected after electrical stimulation of lateral inputs to V1-L2/3 (NR: 11.7 $\pm 0.4 \mathrm{pA}, n=10 ; \mathrm{DE}: 18.2 \pm 2.0 \mathrm{pA}, n=10 ; t$ test: $\left.{ }^{*} p=0.008\right)$. Middle, Example traces of electrical-stimulation-evoked Sr ${ }^{2+}$-mEPSCs. Notations are the same as is Figure 2B. Right, Average electrical-stimulation-evoked Sr ${ }^{2+}$-mEPSCs after subtraction of spontaneous mEPSCS. 


\section{A $\quad \mathrm{V} 1 \mathrm{PV} \rightarrow \mathrm{L} 4$}
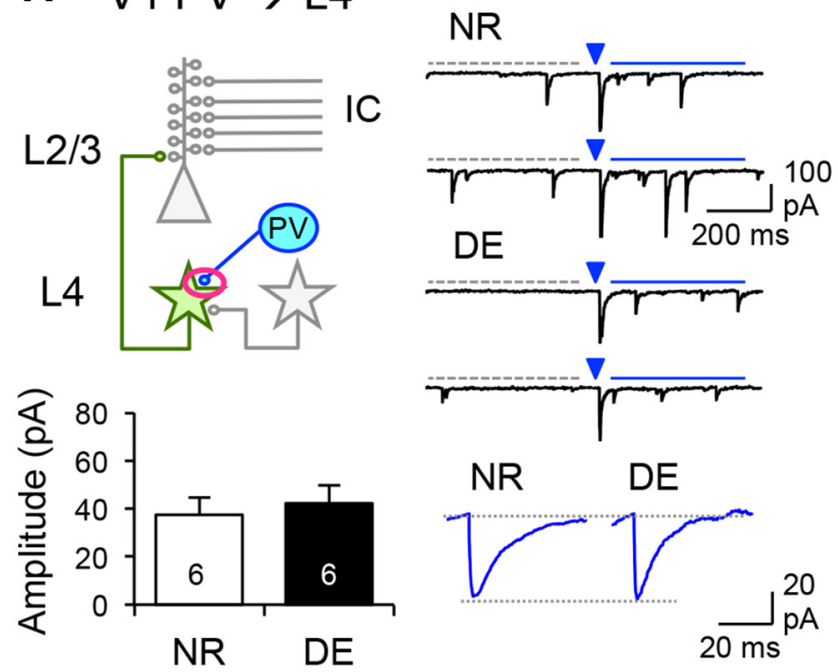

\section{B $\quad \mathrm{V} 1 \mathrm{PV} \rightarrow \mathrm{L} 2 / 3$}
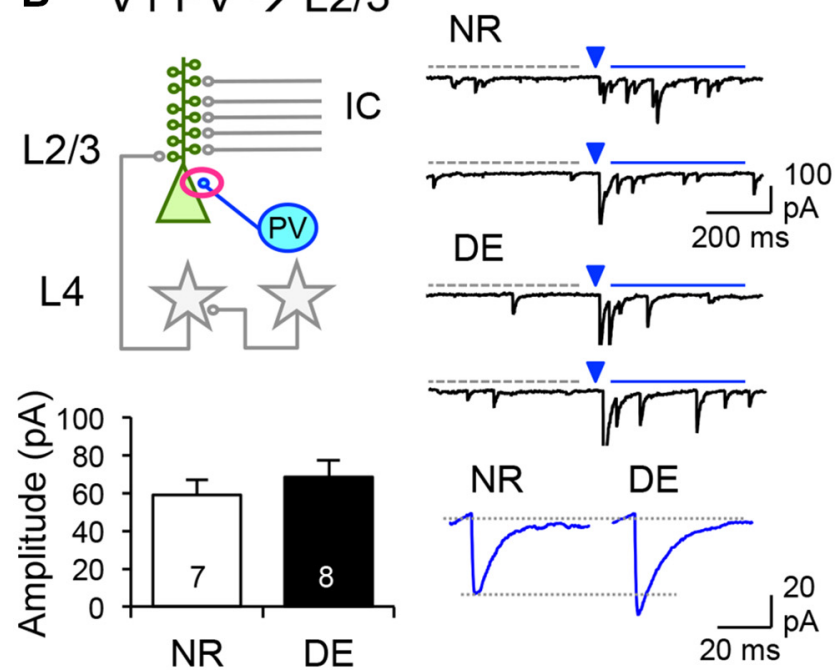

\section{NR}
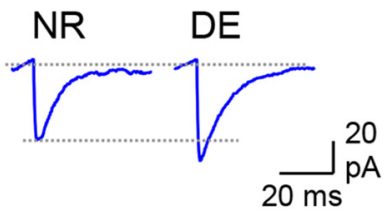

Figure 7. DE does not change $\mathrm{Sr}^{2+}{ }^{+}$mIPSCs evoked from $\mathrm{PV}^{+}$interneurons to principal neurons in $\mathrm{V} 1-\mathrm{L} 4$ or $\mathrm{L} 2 / 3 . A, \mathrm{DE}$ does not alter the strength of $\mathrm{PV}{ }^{+}$synapses to $\mathrm{V} 1-\mathrm{L} 4$ neurons. ChR2 was specifically expressed in PV ${ }^{+}$interneurons by injecting AAV-DI0-ChR2 into PV-Cre mice. Top left, Schematic showing PV ${ }^{+}$inputs onto V1-L4 neurons. Top right, Example lightevoked $\mathrm{Sr}^{2+}{ }^{+}$-mIPSCs from ChR-expressing PV ${ }^{+}$interneurons to V1-L4 principal neurons. Notations are same as in other figures. Bottom left, Comparison of average light-evoked $\mathrm{Sr}^{2+}$ mIPSCs (NR: $56.6 \pm 11.4$ pA, $n=6$; DE: $57.3 \pm 8.34, n=6 ; t$ test: $p=0.96$ ). Bottom right, Average light-evoked $\mathrm{Sr}^{2+}$-mIPSC traces after subtraction of spontaneous mIPSCs (see Materials and Methods for details). $\boldsymbol{B}$, No significant change in the strength of $\mathrm{PV}^{+}$synapses to V1-L2/3 neurons. Top left, Diagram showing PV ${ }^{+}$inputs onto V1-L2/3 neurons. Top right, Example traces of light-evoked $\mathrm{Sr}^{2+}{ }^{2}$-mIPSCs from PV ${ }^{+}$interneurons. Bottom left, Comparison of average light-evoked Sr${ }^{2+}$-mIPSCs (NR: $59.0 \pm 8.2$ pA, $n=7 ; \mathrm{DE}: 68.4 \pm 9.2 \mathrm{pA}, n=8 ; t$ test: $p=0.474)$. Bottom right, Average light-evoked $\mathrm{Sr}^{2+}$-mIPSC traces after subtraction of spontaneous mIPSCs.

to the different functions of evoked versus spontaneous inhibition. Although evoked inhibition in A1-L4 may refine tuning and increase precision, the increase in mIPSC frequency in A1-L2/3 may serve to inhibit tonically subthreshold inputs, which have been suggested to respond to non-CFs (Kaur et al., 2004). If this is the case, then the selective increase in mIPSC frequency in A1L2/3 would suppress non-CF inputs, which could act to further enhance the $\mathrm{CF}$ information carried by FF excitatory inputs. This is consistent with the idea that inhibition in A1-L2/3 acts to narrow tuning properties (Li et al., 2014).

\section{A Adaptation in A1}

B Adaptation in V1
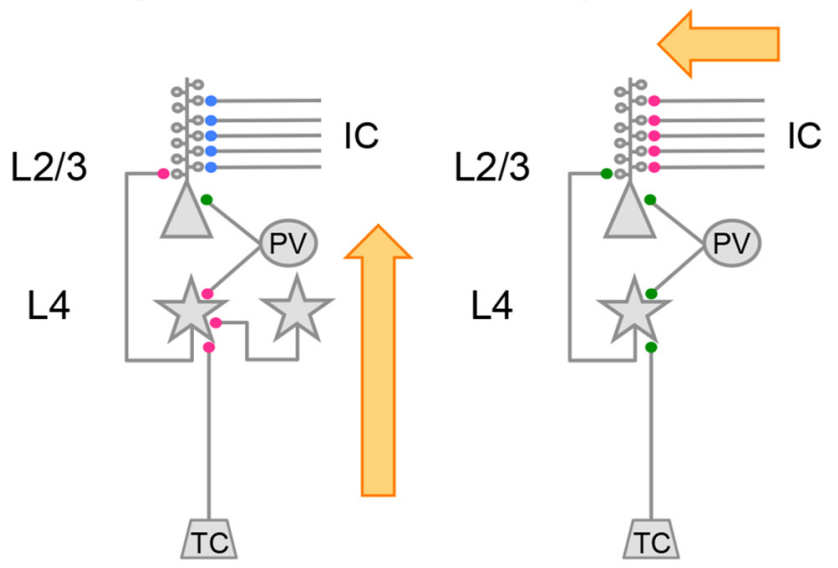

Figure 8. Summary of circuit changes in $\mathrm{A} 1$ and $\mathrm{V} 1$ after DE. $A, \ln \mathrm{A} 1, \mathrm{DE}$ potentiates FF excitatory synapses from the thalamus (thalamocortical inputs, TC) (Petrus et al., 2014) and from $L 4$ to $L 2 / 3$. In addition, recurrent excitatory inputs in $L 4$ potentiate, whereas intracortical (IC) excitatory synapses in L2/3 depress. Inhibitory synaptic transmission to both $L 4$ and L2/3 also increase via different mechanisms. These changes would promote FF processing at the expense of IC inputs. In addition to the changes in excitatory synapses, we found that DE potentiates evoked IPSCs from $\mathrm{PV}^{+}$interneurons to A1-L4. In A1-L2/3, DE did not alter evoked IPSCs from $\mathrm{PV}^{+}$interneurons, but increased the frequency of mIPSCs. Such changes are expected to enhance inhibitory circuit function in A1, which may allow refinement of FF inputs. $\boldsymbol{B}$, In $\mathrm{V} 1, \mathrm{DE}$ does not change the strength of $\mathrm{FF}$ excitatory synapses from the thalamus (TC) (Petrus et al., 2014) nor from L4 to L2/3. In contrast, IC synapses to L2/3 potentiate. There was no significant change in the amplitude of PV-evoked IPSCs in either L2/3 or L4. However, we reported previously that mIPSC frequency in V1-L2/3 neurons decreases with DE (Gao et al., 2010; Gao et al., 2014), which may aid in unmasking IC inputs. Pink circles depict potentiated synapses, blue circles denote depressed synapses, and green circles show synapses that did not show changes in synaptic strength. Orange arrows depict predicted potentiation of information flow based on the synaptic changes.

\section{Adaptation of V1 circuits}

Visual deprivation induced changes in $\mathrm{V} 1$ is qualitatively different from those in $\mathrm{A} 1$ in that it is specific to lateral inputs to $\mathrm{L} 2 / 3$ (Fig. 6) without changes in FF synapses in L2/3 (Fig. 6) or L4 (Petrus et al., 2014). Previous studies showed that, in both V1-L4 and V1-L2/3 neurons, mEPSCs scale up their strengths homeostatically after brief visual deprivation (Desai et al., 2002; Goel et al., 2006; Goel and Lee, 2007; Gao et al., 2010; Goel et al., 2011; He et al., 2012; Petrus and Lee, 2014). Although plasticity in V1-L4 is restricted to a couple of days after eye opening in rodents (Desai et al., 2002), that of V1-L2/3 neurons starts at $\sim$ P21 (Desai et al., 2002 ) and persists through adulthood (Goel and Lee, 2007). DEinduced potentiation of mEPSCs in V1-L2/3 neurons in adults differs from that seen in juveniles in that it is not global and involves a subset of synapses (Goel and Lee, 2007). Here, we report that DE-induced potentiation of V1-L2/3 mEPSCs mainly reflects lateral inputs, and not FF excitatory synapses from L4 (Fig. 6). Even a brief duration of DE is able to trigger metaplasticity to slide down the synaptic modification threshold to promote LTP (Guo et al., 2012). We suggest that the reduction in LTP threshold by DE allows previously weak lateral inputs to potentiate. This would result in input-specific potentiation of lateral inputs, whereas the strength of FF inputs that are devoid of activity would remain unchanged. Although DE did not alter the evoked IPSC amplitude from $\mathrm{PV}^{+}$interneurons (Fig. 7), we reported previously that it decreases the frequency of mIPSCs in V1-L2/3 (Gao et al., 2010; Gao et al., 2014), which could aid in the unmasking of previously subthreshold inputs. Although we have not investigated the source of the lateral inputs to V1-L2/3, it is 
well documented that this layer receives major feedback from higher-order visual areas, especially in adults (Dong et al., 2004). Therefore, we surmise that the potentiation of lateral inputs may amplify previously subthreshold feedback intracortical inputs carrying multisensory information. This would in essence allow V1-L2/3, which is devoid of its primary sensory input, to process other information and may be a cellular substrate for activation of $\mathrm{V} 1$ in blind subjects in response to tactile or auditory information (Bavelier and Neville, 2002).

\section{References}

Atallah BV, Bruns W, Carandini M, Scanziani M (2012) Parvalbuminexpressing interneurons linearly transform cortical responses to visual stimuli. Neuron 73:159-170. CrossRef Medline

Bavelier D, Neville HJ (2002) Cross-modal plasticity: where and how? Nat Rev Neurosci 3:443-452. Medline

Binzegger T, Douglas RJ, Martin KA (2004) A quantitative map of the circuit of cat primary visual cortex. J Neurosci 24:8441-8453. CrossRef Medline

Bruno RM, Sakmann B (2006) Cortex is driven by weak but synchronously active thalamocortical synapses. Science 312:1622-1627. CrossRef Medline

Chattopadhyaya B, Di Cristo G, Wu CZ, Knott G, Kuhlman S, Fu Y, Palmiter RD, Huang ZJ (2007) GAD67-mediated GABA synthesis and signaling regulate inhibitory synaptic innervation in the visual cortex. Neuron 54: 889-903. CrossRef Medline

Cohen LG, Celnik P, Pascual-Leone A, Corwell B, Falz L, Dambrosia J, Honda M, Sadato N, Gerloff C, Catalá MD, Hallett M (1997) Functional relevance of cross-modal plasticity in blind humans. Nature 389:180-183. CrossRef Medline

Crook JM, Eysel UT (1992) GABA-induced inactivation of functionally characterized sites in cat visual cortex (area 18): effects on orientation tuning. J Neurosci 12:1816-1825. Medline

Desai NS, Cudmore RH, Nelson SB, Turrigiano GG (2002) Critical periods for experience-dependent synaptic scaling in visual cortex. Nat Neurosci 5:783-789. Medline

Dong H, Wang Q, Valkova K, Gonchar Y, Burkhalter A (2004) Experiencedependent development of feedforward and feedback circuits between lower and higher areas of mouse visual cortex. Vis Res 44:3389-3400. CrossRef Medline

Douglas RJ, Martin KA (2007) Mapping the matrix: the ways of neocortex. Neuron 56:226-238. CrossRef Medline

Douglas RJ, Koch C, Mahowald M, Martin KA, Suarez HH (1995) Recurrent excitation in neocortical circuits. Science 269:981-985. CrossRef Medline

Gabbott PL, Stewart MG (1987) Distribution of neurons and glia in the visual cortex (area 17) of the adult albino rat: a quantitative description. Neuroscience 21:833-845. CrossRef Medline

Gao M, Sossa K, Song L, Errington L, Cummings L, Hwang H, Kuhl D, Worley P, Lee HK (2010) A specific requirement of Arc/Arg3.1 for visual experience-induced homeostatic synaptic plasticity in mouse primary visual cortex. J Neurosci 30:7168-7178. CrossRef Medline

Gao M, Maynard KR, Chokshi V, Song L, Jacobs C, Wang H, Tran T, Martinowich K, Lee HK (2014) Rebound potentiation of inhibition in juvenile visual cortex requires vision-induced BDNF expression. J Neurosci 34:10770-10779. CrossRef Medline

Gil Z, Connors BW, Amitai Y (1999) Efficacy of thalamocortical and intracortical synaptic connections: quanta, innervation, and reliability. Neuron 23:385-397. CrossRef Medline

Goel A, Lee HK (2007) Persistence of experience-induced homeostatic synaptic plasticity through adulthood in superficial layers of mouse visual cortex. J Neurosci 27:6692-6700. CrossRef Medline

Goel A, Jiang B, Xu LW, Song L, Kirkwood A, Lee HK (2006) Cross-modal regulation of synaptic AMPA receptors in primary sensory cortices by visual experience. Nat Neurosci 9:1001-1003. CrossRef Medline

Goel A, Xu LW, Snyder KP, Song L, Goenaga-Vazquez Y, Megill A, Takamiya K, Huganir RL, Lee HK (2011) Phosphorylation of AMPA receptors is required for sensory deprivation-induced homeostatic synaptic plasticity. PLoS One 6:e18264. CrossRef Medline

Gonchar Y, Burkhalter A (1997) Three distinct families of GABAergic neurons in rat visual cortex. Cereb Cortex 7:347-358. CrossRef Medline
Gougoux F, Lepore F, Lassonde M, Voss P, Zatorre RJ, Belin P (2004) Neuropsychology: pitch discrimination in the early blind. Nature 430:309. Medline

Guo Y, Huang S, de Pasquale R, McGehrin K, Lee HK, Zhao K, Kirkwood A (2012) Dark exposure extends the integration window for spike-timingdependent plasticity. J Neurosci 32:15027-15035. CrossRef Medline

He K, Petrus E, Gammon N, Lee HK (2012) Distinct sensory requirements for unimodal and cross-modal homeostatic synaptic plasticity. J Neurosci 32:8469-8474. CrossRef Medline

Huang ZJ, Kirkwood A, Pizzorusso T, Porciatti V, Morales B, Bear MF, Maffei L, Tonegawa S (1999) BDNF regulates the maturation of inhibition and the critical period of plasticity in mouse visual cortex. Cell 98:739-755. CrossRef Medline

Jiang B, Sohya K, Sarihi A, Yanagawa Y, Tsumoto T (2010a) Laminarspecific maturation of GABAergic transmission and susceptibility to visual deprivation are related to endocannabinoid sensitivity in mouse visual cortex. J Neurosci 30:14261-14272. CrossRef Medline

Jiang B, Huang S, de Pasquale R, Millman D, Song L, Lee HK, Tsumoto T, Kirkwood A (2010b) The maturation of GABAergic transmission in visual cortex requires endocannabinoid-mediated LTD of inhibitory inputs during a critical period. Neuron 66:248-259. CrossRef Medline

Jitsuki S, Takemoto K, Kawasaki T, Tada H, Takahashi A, Becamel C, Sano A, Yuzaki M, Zukin RS, Ziff EB, Kessels HW, Takahashi T (2011) Serotonin mediates cross-modal reorganization of cortical circuits. Neuron 69:780-792. CrossRef Medline

Kaur S, Lazar R, Metherate R (2004) Intracortical pathways determine breadth of subthreshold frequency receptive fields in primary auditory cortex. J Neurophysiol 91:2551-2567. CrossRef Medline

Kuhlman SJ, Olivas ND, Tring E, Ikrar T, Xu X, Trachtenberg JT (2013) A disinhibitory microcircuit initiates critical-period plasticity in the visual cortex. Nature 501:543-546. CrossRef Medline

Li LY, Li YT, Zhou M, Tao HW, Zhang LI (2013) Intracortical multiplication of thalamocortical signals in mouse auditory cortex. Nat Neurosci 16:1179-1181. CrossRef Medline

Li LY, Ji XY, Liang F, Li YT, Xiao Z, Tao HW, Zhang LI (2014) A feedforward inhibitory circuit mediates lateral refinement of sensory representation in upper layer $2 / 3$ of mouse primary auditory cortex. J Neurosci 34:13670-13683. CrossRef Medline

Liu BH, Wu GK, Arbuckle R, Tao HW, Zhang LI (2007) Defining cortical frequency tuning with recurrent excitatory circuitry. Nat Neurosci 10: 1594-1600. CrossRef Medline

Liu BH, Li YT, Ma WP, Pan CJ, Zhang LI, Tao HW (2011) Broad inhibition sharpens orientation selectivity by expanding input dynamic range in mouse simple cells. Neuron 71:542-554. CrossRef Medline

Morales B, Choi SY, Kirkwood A (2002) Dark rearing alters the development of GABAergic transmission in visual cortex. J Neurosci 22:80848090. Medline

Petrus E, Lee HK (2014) BACE1 is necessary for experience-dependent homeostatic synaptic plasticity in visual cortex. Neural Plast 2014:128631. Medline

Petrus E, Isaiah A, Jones AP, Li D, Wang H, Lee HK, Kanold PO (2014) Crossmodal induction of thalamocortical potentiation leads to enhanced information processing in the auditory cortex. Neuron 81:664-673. CrossRef Medline

Pfeffer CK, Xue M, He M, Huang ZJ, Scanziani M (2013) Inhibition of inhibition in visual cortex: the logic of connections between molecularly distinct interneurons. Nat Neurosci 16:1068-1076. CrossRef Medline

Röder B, Teder-Sälejärvi W, Sterr A, Rösler F, Hillyard SA, Neville HJ (1999) Improved auditory spatial tuning in blind humans. Nature 400:162-166. CrossRef Medline

Rudy B, Fishell G, Lee S, Hjerling-Leffler J (2011) Three groups of interneurons account for nearly $100 \%$ of neocortical GABAergic neurons. Dev Neurobiol 71:45-61. CrossRef Medline

Sillito AM (1975) The contribution of inhibitory mechanisms to the receptive field properties of neurones in the striate cortex of the cat. J Physiol 250:305-329. CrossRef Medline

Sterr A, Müller MM, Elbert T, Rockstroh B, Pantev C, Taub E (1998a) Perceptual correlates of changes in cortical representation of fingers in blind multifinger Braille readers. J Neurosci 18:4417-4423. Medline

Sterr A, Müller MM, Elbert T, Rockstroh B, Pantev C, Taub E (1998b) Changed perceptions in Braille readers. Nature 391:134-135. CrossRef Medline 
Stratford KJ, Tarczy-Hornoch K, Martin KA, Bannister NJ, Jack JJ (1996) Excitatory synaptic inputs to spiny stellate cells in cat visual cortex. Nature 382:258-261. CrossRef Medline

Tao HW, Li YT, Zhang LI (2014) Formation of excitation-inhibition balance: inhibition listens and changes its tune. Trends Neurosci 37:528530. CrossRef Medline

Wehr M, Zador AM (2003) Balanced inhibition underlies tuning and sharpens spike timing in auditory cortex. Nature 426:442-446. CrossRef Medline

Whitt JL, Petrus E, Lee HK (2014) Experience-dependent homeostatic synaptic plasticity in neocortex. Neuropharmacology 78:45-54. Medline

Winkowski DE, Kanold PO (2013) Laminar transformation of frequency organization in auditory cortex. J Neurosci 33:1498-1508. CrossRef Medline

Xue M, Atallah BV, Scanziani M (2014) Equalizing excitation-inhibition ratios across visual cortical neurons. Nature 511:596-600. CrossRef Medline

Zhang LI, Zhou Y, Tao HW (2011) Perspectives on: information and coding in mammalian sensory physiology: inhibitory synaptic mechanisms underlying functional diversity in auditory cortex. J Gen Physiol 138:311320. CrossRef Medline

Zheng JJ, Li SJ, Zhang XD, Miao WY, Zhang D, Yao H, Yu X (2014) Oxytocin mediates early experience-dependent cross-modal plasticity in the sensory cortices. Nat Neurosci 17:391-399. CrossRef Medline 